\title{
First-Principles Predictions on Structural Stability, Electronic, Optical, and Thermal Properties of Semiconductors GaNxAs1-x: Materials for Futuristic Optoelectronic Energy Devices
}

Souheyla Gagui ( $\nabla$ souheyla_gagui@yahoo.fr)

Université Larbi Ben M'Hidi Oum El Bouaghi

Sebti Ghemid

Université Badji Mokhtar Annaba

Hocine Meradji

Université Badji Mokhtar Annaba

Beddiaf Zaidi

université Batna 1

Bakhtiar UI Haq

King Khalid University

Rashid Ahmed

UTM Skudai: Universiti Teknologi Malaysia

Bouzid Hadjoudja

Université Badji Mokhtar Annaba

Baghdadi Chouial

Université Badji Mokhtar Annaba

Research Article

Keywords: GaNAs, transition pressure, optical properties, thermal properties.

Posted Date: September 1st, 2021

DOI: https://doi.org/10.21203/rs.3.rs-848653/v1

License: (c) (i) This work is licensed under a Creative Commons Attribution 4.0 International License.

Read Full License 


\title{
First-Principles Predictions on Structural Stability, Electronic, Optical, and Thermal Properties of Semiconductors $\mathrm{GaN}_{\mathrm{x}} \mathrm{As}_{1-\mathrm{x}}$ : Materials for Futuristic Optoelectronic Energy Devices
}

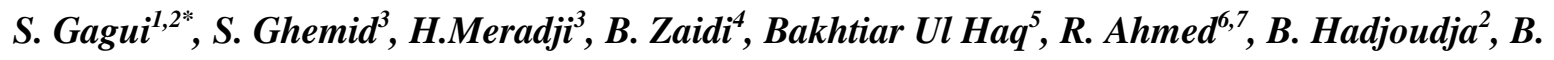 \\ Chouial $^{2}$ \\ ${ }^{1}$ Département des Sciences de la Matière, Université Larbi Ben M'Hidi-Oum El Bouaghi, Algérie \\ ${ }^{2}$ Laboratory of Semiconductors, Department of Physics, University of Badji-Mokhtar, Annaba, Algeria \\ ${ }^{3}$ Laboratoire de Physique des rayonnements, Université Badji Mokhtar, Annaba, Algérie \\ ${ }^{4}$ Department of Physics, Faculty of Material Sciences, University of Batna 1, Batna, Algeria \\ ${ }^{5}$ Advanced Functional Materials \& Optoelectronics Laboratory (AFMOL), Department of Physics, \\ Faculty of Science, King Khalid University, P.O. Box 9004, Abha, Saudi Arabia \\ ${ }^{6}$ Centre for High Energy Physics, Quaid-e-Azam Campus, University of the Punjab, 54590 Lahore, \\ Pakistan \\ ${ }^{7}$ Department of Physics, Faculty of Science, Universiti Teknologi Malaysia, UTM, Skudai, 81310 \\ Johor, Malaysia
}

\begin{abstract}
The knowledge of the physical properties of a material is crucial to realize its practical technological applications. Here, a study related to phase stability, transition pressure, electronic, optical, and thermal properties of GaAs, GaN, as well as their mixed ternary alloys $\mathrm{GaN}_{0.25} \mathrm{As}_{0.75}, \mathrm{GaN}_{0.5} \mathrm{As}_{0.5}$, and $\mathrm{GaN}_{0.75} \mathrm{As}_{0.25}$ is presented. The study is performed by employing "full-potential linearized augmented-plane-wave plus local-orbital, (FP$\mathrm{L}(\mathrm{APW}+\mathrm{lo})$ ) approach framed within density functional theory (DFT)" and recognized within WIEN2k computational code. The results of the phase stability show that the $\mathrm{GaN}_{\mathrm{x}} \mathrm{As}_{1-\mathrm{x}}$ alloys are stable for all compositions in the zinc blende phase (B3), except for $\mathrm{x}=1$, whereas the structure corresponding to $\mathrm{x}=1$ composition is found to be more stable in the wurtzite (B4) phase. The physical properties of the more stable phases corresponding to each composition are explored. The pressure-induced phase transition is also investigated corresponding to each composition. The electronic and optical properties are investigated using the Tran-Blaha modified Becke-Johnson (mBJ) potential approach. To explore the thermal properties, the "quasi-harmonic Debye model" approach is employed. Our calculated results of the absorption coefficients and optical band gap show that these alloys could be appropriate candidates for applications in solar cell and optoelectronic devices.
\end{abstract}


Keywords: GaNAs; transition pressure; optical properties; thermal properties.

*Corresponding Author: Email: souheyla_gagui@yahoo.fr (Souheyla Gagui)

Tel: +213671581237

\section{Introduction}

III-V nitrides binary compounds have shown their potential candidatures for optoelectronics such as light-emitting diodes operating at high temperatures and high-power electronics working for visible to ultraviolet wavelengths [1]. Their alloying has further widened the scope of their applications. More recently, alloys of diluted nitrides have gripped large considerations of material scientists because of showing uncommon physical properties and aspiring device applications as base materials [2], in particular, GaNAs alloys have revealed their great potential for the optoelectronic devices developed on the GaAs substrate $[3,4]$. They have shown their substantial potential for long-wavelength laser diodes with high-level stability at higher temperatures as well [5].

The mutual alloying of GaAs and $\mathrm{GaN}$ is considered to be the panorama of many futuristic optoelectronic applications as well [6]. It has been noticed in several studies that an addition of a very small quantity of nitrogen $(\mathrm{N})$ into GaAs shows an unexpected change in the bandgap energy and an alteration in the electronic band structure resulting in the promising applications of these materials for long-wavelength telecommunications [7, 8]. Moreover, GaAs-based structuring systems are more preferred over the InP-based systems as a distributed Bragg reflector (DBR) mirroring because of their superiority in epitaxial lattice matching for the state-of-the-art short-haul networks components [9]. Investigations in III-V nitrides alloys particularly in $\mathrm{GaN}_{\mathrm{x}} \mathrm{As}_{1-\mathrm{x}}$ have been increased many times owing to the fact of their electronic band structure's sensitivity with the addition of the nitrogen content and resulting in their several applications including high-efficiency solar cells and optoelectronic devices $[\mathbf{1 0}, \mathbf{1 1}]$.

However, GaNAs alloys are found to be inclined to show phase separation, because of the large miscibility gap $[\mathbf{1 2}, \mathbf{1 3}]$, with increasing concentration of the $\mathrm{N}$ resulting in the development of extreme inhomogeneous material alongside the inclusion of the phases of GaAs, GaNAs, and GaN. It means that the growth of good quality diluted nitrides GaNAs alloys are too difficult due to the big miscibility gap between GaAs and GaN. Somehow this problem has been addressed by fabricating GaNAs alloys by molecular beam epitaxial (MBE) 
growth technique using nonequilibrium conditions $[6,12,14]$. Although investigations (theoretical and experimental) are found in the literature to deal with the large miscibility gap between GaN (wurtzite) and GaAs (zincblende), most are related to GaNAs alloying with a low concentration of $\mathrm{N}$ [15] because of big issues of phase separation and aligned large miscibility gap at a large concentration of N. To date not too many studies are found in the literature related to resolve big miscibility gap for the entire range of $\mathrm{x}$ for GaNAs Alloys because of the structural stability issues of the structure of $\mathrm{GaN}$ (wurtzite) and $\mathrm{GaAs}$ (zincblende). This has created a lot of interest for investigations at both (experimental and theoretical) levels in GaNAs [16].

For the fabricated GaNAs alloys, some fundamental studies to investigate compositional variations and surface morphology by MBE technique [17], photoluminescence mechanism at low-temperature GaNAs/GaAs system [6], compositional and structural properties of the superlattices of GaNAs [9], deposition of low-level antimony doped GaNAs on GaAs substrate, enhancement of the optical excellence by inducing hydrogen and epilayers of GaNAs on GaAs are reported in the literature [18-20]. It is also reported that the presence of the bismuth as a surfactant increases the $\mathrm{N}$ concentration in GaNAs alloys up to $60 \%$ by the MBE technique [21]. Studies on the reciprocal space mapping related to GaNAs alloys fabricated via "RF plasma-assisted solid source molecular beam epitaxy" [22], thin-film deposition by pulsed laser of GaNAs [23], and optical properties of the quantum well structures fabricated by migration enhanced epitaxy (MEE) technique of the GaAs/GaNAs system [24] are also reported.

Likewise, Hai et al investigated the electron effective mass of the GaNAs/GaAs quantum well system by the "optically detected cyclotron resonance (ODCR)" technique [25]. Pichanusakorn studied the impact of the type of the dopant and carrier concentration on the coefficients of Seebeck and effective mass of GaNAs alloys thin films [26]. Also, a study of the GaNAs alloys thin films grown by laser pulsed technique and deposited on amorphous and crystalline substrates was carried out by Bedoya et al [23]. Ahmed et al probed the highly resistive regions, created by proton bombardment, in the layers of the sulfur-doped GaAs [10]. Jasinski et al explored the effect of structural defects on the electrical properties of the Si-doped GaNAs made through the $\mathrm{N}$ and $\mathrm{S}$ co-implantation in the GaAs [27]. Potter et al investigated the effect of $\mathrm{N}$ fraction with temperature variations on the emission from the GaNAs/GaAs quantum wells fabricated by MBE technique [28]. Yu et al determined mutual passivation of the isovalent atoms of $\mathrm{N}$ and electrically active group IV of the GaNAs Alloys 
and more recently in another study also it was shown that when Si is doped in GaNAs, the interaction between $\mathrm{Si}$ and $\mathrm{N}$ initiated the mutual passivation resulting in the purging the $\mathrm{Si}$ electrical activity and increase in the bandgap energy [29-32].

Similarly, some theoretical studies also found concerning structural and electronic properties GaNAs alloys [33-35], in another study optoelectronic properties of the GaNAs were predicted [36], structural stability and formation of dislocations issue in GaNAs alloys was explored by employing empirical potential method $[15,37,38]$. A study reported in the literature by the tight-binding (TB) method explores the effect of the resonant state of $\mathrm{N}$ on the electronic bandgap structure of GaNAs alloys [39]. Similarly, the impact of lattice relaxation on the GaNAs alloys' optical properties in a study is reported [40]. In a DFT study, the high-frequency phonon modes, which are because of the Si-N complex created in the zincblende structure of GaAs, are determined [2]. A theoretical analysis of the energy of the wurtzite and zinc blende GaNAs alloys thin films deposited on GaAs was presented by empirical potential approach [38]. Oukli et al analyzed the bandgap reduction in GaNAs alloys [41]. A tight-binding (TB) based analysis by band anti-crossing model in GaNAs alloys is reported [42]. A. H. Reshak investigated dispersion relation for the generation of secondharmonic in GaNAs alloys [43]. Stenuit et al presented a comparative study of the optical transitions in diluted GaNAs alloys by employing ab initio and empirical pseudo-potential approaches [44]. Bi et al predicted the band gap bowing parameter of GaNAs alloys [14]. Although diverse studies are found in the literature to be reported in the literature, as shown above, rare investigations are found in the literature regarding structural stability corresponding to the entire concentration range of $\mathrm{x}$ for GaNxAs1-x alloys by first-principles DFT approach because of the complexity of the structural stability between wurtzite and zincblende of $\mathrm{GaN}$ and GaAs respectively.

In this study, we present a comprehensive study related to structural stability, transition pressure, electronic, optical, and thermal properties of the GaNAs alloys over the entire alloying range of $\mathrm{GaN}$ and GaAs by employing first principles-based computational code WIEN2k which is based on the methodology FP-L(APW+lo) framed within DFT.

\section{Method of Computations}


In order to do our computational work concerning phase stability, transition pressure, electronic, optical, and thermal properties of the $\mathrm{GaN}_{\mathrm{x}} \mathrm{As}_{1-\mathrm{x}}$ alloys for $0 \leq \mathrm{x} \leq 1$, WIEN2k computational code based FP-L(APW+lo) approach designed within DFT was employed [4547]. To obtain the structural parameters, structural stability, and transition pressure, the $\mathrm{Wu}$ Cohen approach for generalized gradient approximation (WC-GGA) was implemented for incorporating exchange-correlation functional part of the total energy calculations (WC-GGA) [48], whereas for determining the electronic and optical properties, modified -Becke-Johnson $(\mathrm{mBJ})$ was used. To do the calculations of electronic band structures and optical properties, the modified Becke-Johnson approach (mBJ) [49] was used being more simple, fast, and robust as well as more accurate to reproduce results for bandgap energy closer to experimental data, particularly for insulators and semiconductors. In this method of computations, at first, for each concentration, a unit cell was simulated. The obtained units were then divided into two regions: interstitial and Muffin tin spheres. Different basis sets are used in both regions to expand crystal potential, wave function as well as charge density. In the Muffin tin spheres, assumed by considering their centres at atomic nuclei, atomic-like wave functions are used for defining their basis set but for the interstitial region, the basis set is termed in plane waves. To expand the wave functions, charge density, and potential defined inside muffin tin spheres, the maximum value of ' $l$ ' was restricted to 10 but for the expansion of plane basis set in the interstitial region, the cut off value of $R_{M T \times} K_{\max }$ was taken equal to 8 which determines the size of the basis set, where $R_{M T}$ represents radii muffin tin (MT) spheres and $K_{\max }$ denotes the maximum value of the wave vector. The charge density and potential in the interstitial region were expanded as a Fourier series by taking the maximum value of lattice vector $\mathrm{G}_{\max }=12(\mathrm{Ryd})^{1 / 2}$. To avoid the muffin tin spheres overlapping, MT values were chosen, 2.17 a.u, 2.17 a.u, and 1.59 a.u for Ga, As, and $\mathrm{N}$ respectively. For further details, cited references from the literature can be consulted [45-47]. 


\section{Results and Discussion}

\subsection{Structural phase stability}

To recognize the structural stability of $\mathrm{GaN}_{\mathrm{x}} \mathrm{As}_{1-\mathrm{x}}$ alloys, in this section we present our computed results of structural parameters which are obtained at the level of WC-GGA approximation. The obtained results of the ground state energy as a function of the unit cell volume for the four phases (rock-salt (B1), $\mathrm{CsCl}$ (B2), zinc-blende (B3), and wurtzite (B4)) of GaAs, $\mathrm{GaN}_{0.25} \mathrm{As}_{0.75}, \mathrm{GaN}_{0.5} \mathrm{As}_{0.5}, \mathrm{GaN}_{0.75} \mathrm{As}_{0.25}$, and $\mathrm{GaN}$ are plotted and shown in Fig.1. From Fig.1, we see that the lowest energy value corresponds to the more stable phase. By following these lines, we see that for the concentrations of $x=0 ; 0.25 ; 0.5 ; 0.75$, zinc-blende (B3) is found to be more stable but for the concentration, $x=1$, wurtzite (B4) phase is found more stable.

To calculate the transition pressure, the relation for the Gibbs free energy relation $(\mathrm{G})$ as given below is used.

$$
\mathrm{G}=\mathrm{E}+\mathrm{PV}-\mathrm{TS}
$$

As the calculations within DFT are carried out at absolute zero $(\mathrm{T}=0 \mathrm{~K})$, therefore, the abovesaid relation (1) reduces to $\mathrm{G}=\mathrm{E}+\mathrm{PV}$, which is also equivalent to the enthalpy of formation (H) that is $\mathrm{H}=\mathrm{E}+\mathrm{PV}$ [50]. Then the value of the transition pressure from the abovementioned enthalpy relation was calculated as a function of pressure for the four (B1, B2, B3, and B4) phases of $\mathrm{GaN}_{\mathrm{x}} \mathrm{As}_{1-\mathrm{x}}$ shown as in Fig. 2. The obtained results of pressures corresponding to phase transitions from our calculations are collected in Table $\mathbf{1}$ along with previously reported experimental and theoretical data. Our result shows that the phase transition of GaAs from phase $\mathrm{B} 3$ to phase $\mathrm{B} 1$ is taking place at $\mathrm{P}_{\mathrm{t} 1}=12.270 \mathrm{GPa}$ which is somehow lower than the reported experimental measurements [51, 52] as well as some theoretical studies [53-56]. However, it shows a good agreement with the previously reported studies $[\mathbf{5 7}, \mathbf{5 8}]$. On the other hand, for the $\mathrm{GaN}$ transition pressure for $\mathrm{B} 3$ to $\mathrm{B} 1$ is found at 43.958 GPa, in agreement with the reported experimental measurements [59] and some of the theoretical studies [61-63], but somewhat are higher than the results reported in some other studies [56, 64-66]. The transition pressure of B4 to the structure B1 is found to be 48.345 GPa which is somewhat higher than the experimental measurements [68] and lower than the study reported in reference [69], however, somehow are higher than the theoretical study as reported in references $[\mathbf{6 3}, \mathbf{6 6}, \mathbf{6 9}]$. For the others, phase transition (B3 to B2, B4 to B1, and 
B4 to B2 and B1 to B2) for the two binary (GaAs and GaN) compounds, in literature no experimental/theoretical study is available for comparison. For their mixed $\mathrm{GaN}_{\mathrm{x}} \mathrm{As}_{1-\mathrm{x}}$ alloys, there is also no study available for comparison to our knowledge.

We also calculated $\Delta \mathrm{E}_{0}\left(\mathrm{E}_{0 \mathrm{~B} 3}-\mathrm{E}_{0 \mathrm{~B} 4}\right)$ for each concentration of $\mathrm{x}$. The concentration at which the phase transition occurs is shown in Fig. 3. From Fig. 3, it can be seen that the transition occurs from phase $\mathrm{B} 3$ to $\mathrm{B} 4$ at $\mathrm{x}=0.98$. The schematic crystal structures for different compositions of $\mathrm{GaN}_{\mathrm{x}} \mathrm{As}_{1-\mathrm{x}}$ alloys are shown in Fig. 4. The obtained results for the total energy, for different phases of $\mathrm{GaN}_{\mathrm{x}} \mathrm{As}_{1-\mathrm{x}}$ alloys, with respect to the volume are then fitted to the "Birch-Murnaghan equation of states" [70]. The optimized results for the lattice constants (a), bulk moduli (B) values, and their pressure derivatives (B'), are consequently determined from the optimized phases of $\mathrm{GaN}_{\mathrm{x}} \mathrm{As}_{1-\mathrm{x}}$ alloys materials which are shown in Table 2. Hence Table 2 summarizes our calculated results along with previously reported results to make a comparison. Our results for the lattice parameters $(a)$ of GaAs in its zinc-blende phase (B3) are in good agreement with the experiments [71-74] and theoretical [35, 57, 76, 77] calculations but for B, our results slightly lesser than the experimental measurements [72, 74, 75] and are found in nice agreement with the theoretical studies [35, 76, 57]. Our results for B are found in good agreement with the reported data in literature where available [76-78, 80]. Our results for (a) concerning the $\mathrm{GaN}_{0.25} \mathrm{As}_{0.75}, \mathrm{GaN}_{0.5} \mathrm{As}_{0.5}$, and $\mathrm{GaN}_{0.75} \mathrm{As}_{0.25}$ alloys in their B3 phase are found in nice agreement with the theoretical data, but for B our values are slightly higher than the theoretical results, for their other three phases, no results neither experimental nor theoretical are available to make the comparison for alloys and the binary compound $\mathrm{GaN}$, our results for the three phases (B1, B3, and B4) are found to be a good one.

\subsection{Electronic properties}

\subsubsection{Band structures}

It is very important to investigate the electronic properties of any semiconductor, in particular, its energy band gap, theoretically as well as experimentally before it using as a base material in an electronic device, to investigate its relevance in such a manufacturing treat. We, therefore, determined the band structures of the stable phases of the $\mathrm{GaN}_{\mathrm{x}} \mathrm{As}_{1-\mathrm{x}}$ alloys using the mBJ scheme, as we already have been predicted that B3 is the most stable for the compositions GaAs, $\mathrm{GaN}_{0.25} \mathrm{As}_{0.75}, \mathrm{GaN}_{0.5} \mathrm{As}_{0.5}$, and $\mathrm{GaN}_{0.75} \mathrm{As}_{0.25}$ and $\mathrm{B} 4$ for the composition $\mathrm{x}=1$, that is, for $\mathrm{GaN}$ as represented in Fig. 5, From Fig. 5, we see that all of the alloys compositions show their direct bandgap nature at $\Gamma$ point as endorsing the study performed by 
H. Baaziz et al. [33] for concentration $\mathrm{x}=0,0.25$, and 0.5 for B3 phase, whereas its variation as a function of the nitrogen concentration can be seen from the Fig. 6. As can be seen from Fig. 6 that the energy gap values decrease up to $x=0.25$ and then it is increased with the increasing concentration of the $x$. The reduction in the bandgap energy up to $x=0.25$ is described in terms of its highly localized nature as this perturbation was introduced by atoms of $\mathrm{N}$ [97-102], Moreover, the variation of $\mathrm{E}_{\mathrm{g}}(\mathrm{x})$ of $\mathrm{GaN}_{\mathrm{x}} \mathrm{As}_{1-\mathrm{x}}$ is found very similar to obtained by H. Baaziz et al using LDA, GGA, and EVGGA [33]. Our results obtained for the energy band gaps with stable phase are collected in Table 3. The results of previously reported calculations and experimental data are also tabulated in Table $\mathbf{3}$ for comparison. We notice that our values of the band gaps obtained by $\mathrm{mBJ}$ are closer to the experimental measurements and previously reported theoretical results for binary compounds GaAs and $\mathrm{GaN}$. However, on mixed alloys of $\mathrm{GaN}_{\mathrm{x}} \mathrm{As}_{1-\mathrm{x}}$ alloys, no experimental study is found in the literature yet, however, our computed results are in reasonable agreement with the results reported by M. Ziane et al. [35] but are little higher than the results obtained by H. Baaziz et al at the level of EV-GGA approximation [33]. This nonlinear variation in the bandgap energy for $\mathrm{GaN}_{\mathrm{x}} \mathrm{As}_{1-\mathrm{x}}$ alloys leads to the bowing parameter. To calculate the value of the bowing parameter corresponding to bandgap energy for $\mathrm{GaN}_{\mathrm{x}} \mathrm{As}_{1-\mathrm{x}}$ alloys, the computed data is fitted as a function of $\mathrm{N}$ concentration in the following equation:

$E_{g}^{m B J}=1.444-2.971 x+4.787 x^{2}$

From our calculations, we found the value of the bowing parameter equal to $4.787 \mathrm{eV}$ at the level of the mBJ scheme.

\subsubsection{Density of states}

The total and partial density of states are calculated for $\mathrm{GaN}_{\mathrm{x}} \mathrm{As}_{1-\mathrm{x}}$ with $\mathrm{x}=0,0.25,0.5$ and $\mathrm{x}=0.75$ in the zinc-blende phase whereas for $\mathrm{x}=1$ in the wurtzite phase using $\mathrm{mBJ}$ approximation as shown in Fig. 7. From Fig. 7, the plotted data of the partial density of states for GaAs displays the divergence of the valence band into two parts. The first part from $11.348 \mathrm{eV}$ to $-9.879 \mathrm{eV}$ is dominated by the main contributions of the s-As orbitals, where the second region from $-6.325 \mathrm{eV}$ to Fermi level $\left(\mathrm{E}_{\mathrm{F}}\right)$ of the valence band is shaped from the main contributions of s- $\mathrm{Ga}$ and $\mathrm{p}$-As orbitals. The formation of the conduction band is predominantly contributed by the s-Ga, $\mathrm{p}-\mathrm{Ga}$, and $\mathrm{p}$-As. The results obtained in this work are almost similar to the obtained results by Moussa et al within mBJ approximation [77] and 
Baaziz et al. through EV-GGA approximation [33]. The orbital density of states for GaN shows that the region of the valence band from $-13.38 \mathrm{eV}$ to $-11.47 \mathrm{eV}$ is mainly dominated by $\mathrm{s}-\mathrm{N}$ and p-N states, the valence band near the Fermi level $\left(-6.13 \mathrm{eV}\right.$ to $\left.\mathrm{E}_{\mathrm{F}}\right)$ is formed by the main contributions of $\mathrm{p}-\mathrm{N}$. However, in the conduction band, the main contribution is $\mathrm{p}-\mathrm{N}$ states, however, no experimental/theoretical evidence is found in the literature for comparison for the B4 phase of GaN. For the mixed alloys, $\mathrm{GaN}_{0.25} \mathrm{As}_{0.75}, \mathrm{GaN}_{0.5} \mathrm{As}_{0.5}$, and $\mathrm{GaN}_{0.75} \mathrm{As}_{0.25}$, we see that the total and partial density of states are the same, that is, the valence band from $11.779 \mathrm{eV}$ to $-10.059 \mathrm{eV}$ is found to be made mainly from the contributions of the s-Ga, s-As, and s-N states. The part of the valence band from $-6.592 \mathrm{eV}$ to Fermi level is dominantly shaped by s and p states of the atoms of $\mathrm{Ga}$, As, and $\mathrm{N}$ present in the alloy's composition. Similarly, the conduction band is mainly formed by s and p states of the atoms (Ga, As, and $\mathrm{N})$ present in the composition of the alloys.

\subsection{Optical properties}

To investigate the optical behavior of the investigated alloys, both the real $\left(\varepsilon_{1}(\omega)\right) \&$ imaginary $\left(\varepsilon_{2}(\omega)\right)$ parts of the dielectric function $\varepsilon(\omega)$ are computed by employing the Kramer-Krong approach as given in the literature [112] and reported in the following relations:

$\varepsilon_{2}(\omega)=\frac{V e^{2}}{2 \pi \hbar m^{2} \omega^{2}} \int d^{3} k \sum_{n n^{\prime}}\left|\left\langle k n|p| k n^{\prime}\right\rangle\right|^{2} f(k n) \times\left[1-f\left(k n^{\prime}\right)\right] \partial\left(E_{k n}-E_{k n^{\prime}}-\hbar \omega\right)$

$\varepsilon_{1}(\omega)=1+\frac{2}{\pi} \int_{0}^{\infty} \frac{\varepsilon_{2}(\omega \prime) \omega \prime d \omega \prime}{\omega^{\prime 2}-\omega^{2}}$

Where $\hbar \omega$ relation describes the photon energy, p is used to denote the momentum operator which is described as $\mathrm{p}=(\hbar / i)(\partial / \partial x), \mid k n>, E_{k n}$ corresponds to eigenfunction and $f(k n)$ denotes Fermi distribution function. However, microscopic optical parameters for example reflectivity $R(\omega)$, refractive index $n(\omega)$, and absorption coefficient $\alpha(\omega)$ are derived from $\varepsilon_{1}(\omega)$ and $\varepsilon_{2}(\omega)$ by using relations given in the follows:

$$
\begin{aligned}
& n(\omega)=\frac{1}{\sqrt{2}}\left[\sqrt{\varepsilon_{1}^{2}(\omega)+\varepsilon_{2}^{2}(\omega)}+\varepsilon_{1}(\omega)\right]^{1 / 2} \\
& R(\omega)=\left[\frac{\sqrt{\varepsilon_{1}^{2}(\omega)+j \varepsilon_{2}^{2}(\omega)}-1}{\sqrt{\varepsilon_{1}^{2}(\omega)+j \varepsilon_{2}^{2}(\omega)}+1}\right]^{2}
\end{aligned}
$$




$$
\begin{aligned}
& \alpha(\omega)=\sqrt{2 \omega}\left[\sqrt{\varepsilon_{1}^{2}(\omega)+\varepsilon_{2}^{2}(\omega)}-\varepsilon_{1}(\omega)\right]^{1 / 2} \\
& \sigma(\omega)=\frac{\omega}{4 \pi} \varepsilon_{2}(\omega) \\
& L(\omega)=\frac{\varepsilon_{2}(\omega)}{\varepsilon_{1}(\omega)^{2}+\varepsilon_{2}(\omega)^{2}}
\end{aligned}
$$

At frequency zero, the static refractive index value is appraised by the following relation:

$$
n(0)=\sqrt{\varepsilon_{1}(0)}
$$

To confirm the accuracy of our results, the following additional models have also been employed to calculate optical properties:

a) Herve and Vandamme's relation [113] is as given below:

$$
n=\sqrt{1+\left(\frac{A}{E_{g}+\beta}\right)^{2}}
$$

Were $A=13.6$ and $\beta=3.4 \mathrm{eV}$.

b) Ravindra, Auluk, and Srivastava relation are described in the following [114]:

$$
n=\alpha+\beta E_{g}
$$

With $\alpha=4.084$ and $\beta=-0.62 \mathrm{eV}^{-1}$

c) Moss formula for the atomic model is given by the following relation [115]:

$$
E_{g} n^{4}=k
$$

In the relation above, $E_{g}$ and $k$ denote the bandgap energy and constant $=108 \mathrm{eV}$ respectively.

Fig. 8, Show the variation of $\varepsilon_{1}(\omega)$ versus energy $(0-40 \mathrm{eV})$ for different compositions of $\mathrm{N}$ i.e $\mathrm{GaP}, \mathrm{GaP}_{0.75} \mathrm{~N}_{0.25}, \mathrm{GaP}_{0.5} \mathrm{~N}_{0.5}, \mathrm{GaP}_{0.25} \mathrm{~N}_{0.75}$, and $\mathrm{GaN}$ for their stable structures using $\mathrm{mBJ}$ approximation. We notice $\varepsilon_{1 x x}(\omega)$ in $\mathrm{x}$-direction almost is equal $\varepsilon_{1 z z}(\omega)$ for $\mathrm{z}$-direction for $\mathrm{x}$ $=0.5$ and $\mathrm{x}=1$. We also observe that $\varepsilon_{1}(\omega)$ is substantially high for highest peaks lying at $2.898 \mathrm{eV}$ (17.036), $2.571 \mathrm{eV}$ (12.036), $3.088 \mathrm{eV}$ (11.170), 4.421eV (10.072) and $6.816 \mathrm{eV}$ (7.368) corresponding to $\mathrm{x}=0,0.25,0.5,0.75$ and 1 respectively. And then it decreases to zero at the energy points $4.83 \mathrm{eV}, 5.415 \mathrm{eV}, 6.794 \mathrm{eV}, 7.956 \mathrm{eV}$, and $12.177 \mathrm{eV}$ for $\mathrm{x}=0$, $0.25,0.5,0.75$, and 1 respectively, and in the interval $(4.83 \mathrm{eV}-23.292 \mathrm{eV})$ its values become negative showing a signature of metallic behavior in this range of energy for mentioned concentrations of the alloys and the reflection of the incident electromagnetic radiations in this spectral range. Beyond $15.077 \mathrm{eV}$, then the spectra of $\varepsilon_{1}(\omega)$ become 
somewhat positive. Our results for maximum and zero values of the real part of the dielectric for GaAs are in good agreement with the values $(2.522 \mathrm{eV}$ and $4.642 \mathrm{eV})$ reported already in reference [57]. The variation in $\varepsilon_{1}(\omega)$ is also analogous to the reported results in the range (0$40 \mathrm{eV}$ ) previously [57], obtained results by Moussa et al (in the range 0-14 eV) [77] and obtained results by Ziane et al. (in the range 0-15eV) [76] using mBJ-LDA approximation for GaAs, are also similar compared to the results of Reshak et al [40] obtained through EV-GGA approach for $\mathrm{GaN}_{0.25} \mathrm{As}_{0.75}, \mathrm{GaN}_{0.5} \mathrm{As}_{0.5}$ and $\mathrm{Ga} \mathrm{N}_{0.75} \mathrm{As}_{0.25}$ for energy interval $(0-15 \mathrm{eV})$. The obtained results at $\varepsilon_{1}(0)$ are shown in Table 4 with the results obtained from other models ( Herve., Ravindra, Moss.) as well. Our results obtained of static dielectric constant $\varepsilon_{1}(0)$ for GaAs are lower than the theoretical models (Herve., and Moss.) and are closer to (Ravindra) and slightly less than the reported experimental [116] and theoretical values in the literature [57], however, it is a good agreement with references [106, 76]. Our results for the concentrations $\mathrm{x}=0.25 ; 0.5 ; 0.75$ are lower than the other theoretical models and theoretical data as well $[36,40]$. While for the GaN compound our results are closer to (Ravindra) and the theoretical value [91].

For all the other optical quantities calculated in Figs. 9-14, we note no appreciable difference in the values obtained in the $\mathrm{x}$ and $\mathrm{z}$ directions.

Fig. 9 shows the plots for the imaginary part of the dielectric function $\varepsilon_{2}(\omega)$ vs energy $(0-40$ $\mathrm{eV}$ ) for $\mathrm{GaN}_{\mathrm{x}} \mathrm{As}_{1-\mathrm{x}}$ alloys. From the Fig. 9, we find the optical absorption edges at $1.537 \mathrm{eV}$, $0.721 \mathrm{eV}, 1.292 \mathrm{eV}, 2.000 \mathrm{eV}, 3.170 \mathrm{eV}$ for GaAs, GaN $0.25 \mathrm{As}_{0.75}, \mathrm{GaN}_{0.5} \mathrm{As}_{0.5}, \mathrm{GaN}_{0.75} \mathrm{As}_{0.25}$ and $\mathrm{GaN}$ respectively. These values are found to be consistent with the obtained results of the electronic bandgap energy from the analysis of the respective electronic band structures of such alloys as shown in Table 3. Our results for GaAs are also in good agreement with the results reported by Ziane et al. $(1.7 \mathrm{eV})$ using mBJ-LDA [76]. However, our results for $\mathrm{x}=$ $0.25,0.5$ and 0.75 are superior to the results of Reshak et al. $(0.38,0.65$ and $1.18 \mathrm{eV})$ respectively [40]. On other hand, these results agree with the theoretical value $(3.68 \mathrm{eV})$ obtained by Haq et al [91] using mBJ potential for compound $\mathrm{GaN}$ in the structure (B4). We observe from the plots that the highest peaks are found at energies $4.721 \mathrm{eV}$ (23.607), 5.075 $\mathrm{eV}$ (16.178), $5.864 \mathrm{eV}$ (12.685), $6.136 \mathrm{eV}(10.715)$ and $12.694 \mathrm{eV}(7.274)$ for $\mathrm{x}=0,0.25,0.5$, 0.75 and 1 respectively. Our results for $x=0$ are in good agreement with the already reported results $(4.526 \mathrm{eV})$ by mBJ-GGA approximation [57] by Touam et al. (26.50 at $4.32 \mathrm{eV})$ [58], Ziane et al. (4.88 eV) [76] and Moussa et al. (4.20eV) via mBJ-LDA [77]. Moreover, the variation of $\varepsilon_{2}(\omega)$ for $\mathrm{x}=0$ and for $\mathrm{x}=0.25,0.5,0.75$ for structure (B3) is closely matching with the previous reports $[\mathbf{4 0 , 5 7 , 5 8 , 7 6 , 7 7 ]}$, and for $x=1$ in structure $(B 4)$ with ref [91]. 
Fig. 10 presents the spectra of the refractive index $n(\omega)$ for energy range, $0-40 \mathrm{eV}$, it is also related to $\varepsilon(0)$ by the relation 10 . One can notes that the strong peaks are at the energies 2.925 $\mathrm{eV}$ (4.210) for GaAs, $3.768 \mathrm{eV}$ ( 3.599) for $\mathrm{GaN}_{0.25} \mathrm{As}_{0.75}, 3.306 \mathrm{eV}$ (3.395) for $\mathrm{GaN}_{0.5} \mathrm{As}_{0.5}$, $4.476 \mathrm{eV}$ (3.246) for $\mathrm{GaN}_{0.75} \mathrm{As}_{0.25}$ and 6.952eV (3.014) for GaN. Our results for GaAs are in good agreement with the results of $2.554 \mathrm{eV}$ [57] and by Touam et al. (2.27 eV) [58]. Moreover, the variation of $\mathrm{n}(\omega)$ of GaAs is also similar as reported already in references [57, 58]. However, for the $\mathrm{GaN}$ and mixed alloys $\mathrm{GaN}_{\mathrm{x}} \mathrm{As}_{1-\mathrm{x}}$, no report is found in the literature. Our computed results for static refractive indices $\mathrm{n}(0)$ are shown in Table 4, along with previously reported theoretical and experimental data. We see, our results for GaAs are in nice agreement with the experimental measurements [116], empirical models Ravindra and theoretical results where available $[57,77, \mathbf{1 0 6}, \mathbf{1 1 7}]$ in the literature. For GaN our results are in agreement with empirical models and with the ref [91]. However, on the mixed alloys of $\mathrm{GaN}_{\mathrm{x}} \mathrm{As}_{1-\mathrm{x}}$ alloys, no report is found in the literature and agrees with the theoretical models for all the concentrations except for $\mathrm{x}=0.5$ where our results are lower than other theoretical models as well.

Fig. 11 presents the spectra of the absorption coefficient $\alpha(\omega)$ for $\mathrm{GaN}_{\mathrm{x}} \mathrm{As}_{1-\mathrm{x}}$ alloys in the energy range 0-40 eV. From Fig. 11, one can note, at the energy below the bandgap values, absorption is zero. Similarly, absorption is also in the visible region but it reaches its maximum value in the Ultra-Violet region, showing that absorption starts after the bandgap edge energy for each composition $\mathrm{x}$, and continues up to $22.49 \mathrm{eV}, 24.694 \mathrm{eV}, 25.864 \mathrm{eV}$, $26.737 \mathrm{eV}$, and $30.29 \mathrm{eV}$ for $\mathrm{x}=0,0.25,0.5,0.75$ and 1 respectively, meaning that the absorption of electromagnetic radiation continues for a wider range of energy. Moreover, the variation of $\alpha(\omega)$ of GaAs in structure (B3) is closely matching to previously reported results for an energy range (0-40eV) [57] and Ziane et al. (0-7eV) [76], Also for alloys $\mathrm{GaN}_{0.25} \mathrm{As}_{0.75}$, $\mathrm{GaN}_{0.5} \mathrm{As}_{0.5}$ and $\mathrm{GaN}_{0.75} \mathrm{As}_{0.25}$ in structure (B3) is similar to Reshak et al. (0-15eV) [40], but for $\mathrm{GaN}$ (B4) no results available for comparison.

Fig. 12 shows the variation of $R(\omega)$ of $\mathrm{GaN}_{\mathrm{x}} \mathrm{As}_{1-\mathrm{x}}$ in the range $0-40 \mathrm{eV}$. The maximum reflectivity values are approximately for $\mathrm{GaAs}(57.1 \%$ at $5.07 \mathrm{eV}), \mathrm{GaN}_{0.25} \mathrm{As}_{0.75}(54 \%$ at $8.834 \mathrm{eV}), \mathrm{GaN}_{0.5} \mathrm{As}_{0.5}(56.4 \%$ at 12.285$), \mathrm{GaN}_{0.75} \mathrm{As}_{0.25}(53 \%$ at 12.53$)$ and $\mathrm{GaN}(56.9 \%$ at 13.238). Our results obtained for GaAs are in reasonable agreement with previously reported theoretical data by Gagui et al. (55.39\%) [57], by Touam et al. (60\% at 4.57eV) [58], and by Ziane et al. $(62 \%$ at $4.95 \mathrm{eV})$ [76]. Also from this figure we notice that the reflectivity is found for a wide range up to $19.66 \mathrm{eV}, 19.877 \mathrm{eV}, 23.36 \mathrm{eV}, 26.626 \mathrm{eV}$ and $27.742 \mathrm{eV}$ for ( $\mathrm{x}$ $=0 ; 0.25,05 ; 0.75$ and 1 respectively). Additionally, our computed results for $\mathrm{R}(0)$ are shown 
in Table 4. We notice that our values of $\mathrm{R}(0)$ decrease as the concentration of $\mathrm{N}$ increases and the results obtained for GaAs are consistent with the reported results in ref [57], and for their alloys, we see that our results are slightly lower than the ref [40], moreover for GaN in structure (B4) no results available for comparison. Also, the variation of $R(\omega)$ of GaAs is closely matching to previously reported results for an energy range of $0-40 \mathrm{eV}$ by Gagui et al. [57], by Touam et al. (0-35eV) [58] and Ziane et al. (0-7eV) [76].

Fig. 13 displays the results of the optical conductivity $\sigma(\omega)$ versus photon energy for different alloys compositions with $\mathrm{N}$ concentrations, $\mathrm{x}=0,0.25,0.5,0.75$, and 1. From Fig. 13, we found that the maximum value of the conductivity is nearly $15091.3(\Omega \mathrm{m})^{-1}$ at $4.748 \mathrm{eV}$ for $\mathrm{x}=0,11113(\Omega \mathrm{m})^{-1}$ at $5.129 \mathrm{eV}$ for $\mathrm{x}=0.25,10047.5(\Omega \mathrm{m})^{-1}$ at $5.891 \mathrm{eV}$ for $\mathrm{x}=0.5$, $8844.28(\Omega \mathrm{m})^{-1}$ at 6.1361 for $\mathrm{x}=0.75$ and $12421.8(\Omega \mathrm{m})^{-1}$ at $12.694 \mathrm{eV}$ for $\mathrm{x}=1$. Next to these values of photon energy, optical conductivity for each reported concentration of $\mathrm{N}$ start decreasing. Our obtained results for GaAs are in reasonable agreement with previously reported results (13007.461 at $4.529 \mathrm{eV})$ [57] along with the variation of $\sigma(\omega)$ as a function of photon frequency.

Fig. 14 displays the plots of variation of $\mathrm{L}(\omega)$ of $\mathrm{GaN}_{\mathrm{x}} \mathrm{As}_{1-\mathrm{x}}$ in the range $0-40 \mathrm{eV}$. From Fig. 14, we notice that the main peaks are located around $16.585 \mathrm{eV}$ for $\mathrm{GaAs}$, for $\mathrm{GaN}_{0.25} \mathrm{As}_{0.75}$ at $16.884 \mathrm{eV}$, for $\mathrm{GaN}_{0.5} \mathrm{As}_{0.5}$ at $16.805 \mathrm{eV}$, for $\mathrm{GaN}_{0.75} \mathrm{As}_{0.25}$ at $21.483 \mathrm{eV}$, and for $\mathrm{GaN}$ at $23.088 \mathrm{eV}(>12 \mathrm{eV}$ ) which corresponds to plasma resonance frequency [118] and showing that these peaks are corresponding to the minimum values of imaginary and zero value of real part of the dielectric function[119]. However, our results are slightly higher than other theoretical one obtained by Touam et al. (15.94eV) for GaAs [58] but the variation in the value of the $\mathrm{L}(\omega)$ of GaAs is similar as already reported in ref [58].

\subsection{Thermal properties}

Investigations of the thermal properties deliver knowledge regarding the behavior of a material at different temperatures. In the following, obtained results, in this study, of the thermal properties for $\mathrm{GaN}_{\mathrm{x}} \mathrm{As}_{1-\mathrm{x}}$ alloys are discussed. The results are obtained using the Gibbs program reported in the literature [120] and are based on the "quasi-harmonic Debye model". Gibbs function $\left(\mathrm{G}^{*}(\mathrm{~V}, \mathrm{P}, \mathrm{T})\right)$ is determined by summing up the total energy per unit cell, vibrational Helmholtz free energy, and constant hydrostatic value of PV, for any crystalline material under nonequilibrium conditions as given below:

$G(V, P, T)=E(V)+P V+A_{V i b}\left[\theta_{D}(V), T\right]$ 
By applying the Debye model, $A_{V i b}$ (the vibrational portion of the Gibbs function) is computed by employing the relation based on phonon density of states of the materials [121, 122] as given below:

$A_{V i b}\left(\theta_{D}, T\right)=n K_{B} T\left[\frac{9 \theta_{D}}{8 T}+3 \ln \left(1-e^{-\left(\theta_{D} / T\right)}-D\left(\theta_{D} / T\right)\right)\right]$

Where $\left(\theta_{\mathrm{D}} / \mathrm{T}\right)$ represents the Debye model and $n$ denotes the number of atoms per formula unit. However, for an isotropic solid, $\theta_{\mathrm{D}}$ (Debye temperature) is determined by using the following relation reported in the literature [121]:

$\theta_{D}=\frac{\hbar}{K_{B}}\left[6 \pi^{2} V^{1 / 2 n}\right]^{1 / 3} f(\sigma) \sqrt{\frac{B_{S}}{M}}$

Where $M$ and $B s$ denote molecular mass/unit cell and bulk modulus (adiabatic). The relation give in reference [120] for $\mathrm{Bs}$ show that $\mathrm{Bs} \cong B(V)$ i.e.

$B_{S} \cong B(V)=V\left\{\frac{d^{2} E(V)}{d V^{2}}\right\}$

And $\mathrm{f}(\sigma)$ is described as:

$f(\sigma)=\left\{3\left[2\left(\frac{21+\sigma}{31-2 \sigma}\right)^{3 / 2}+\left(\frac{11+\sigma}{31-\sigma}\right)^{3 / 2}\right]^{-1}\right\}^{1 / 3}$

Where $\sigma$ denotes the Poisson ratio i.e. 0.25 [123].

For nonequilibrium conditions, the minimization of the $\mathrm{G}^{*}(\mathrm{~V} ; \mathrm{P}, \mathrm{T})$ with respect to $\mathrm{V}$ is obtained as follows:

$\left[\frac{\partial G^{*}(V ; P, T)}{\partial V}\right]_{P, T}=0$

By getting the solution of the eq. 17, the $\mathrm{V}(\mathrm{P}, \mathrm{T})$, equilibrium curve, and thermal equation of state are obtained. But bulk modulus for isothermal conditions $\left(\mathrm{B}_{\mathrm{T}}\right)$, specific heat capacity at constant volume $\left(\mathrm{CV}_{\mathrm{V}}\right)$, and entropy $(\mathrm{S})$ are determined by the following relations as given in the literature [120]:

$B_{T}(P, V)=V\left(\frac{\delta^{2} G^{*}(V ; P, T)}{\delta V^{2}}\right)_{P, T}$

$C_{V}=3 n K\left[4 D\left(\frac{\theta}{T}-\frac{3 \theta / T}{e^{\theta / T-1}}\right)\right]$

$S=n k\left[4 D\left(\frac{\theta}{T}\right)-3 \ln \left(1-e^{-\theta / T}\right)\right]$

Using the "quasi-harmonic Debye model" and retrieved data from the E-V curve, different thermodynamic parameters at different pressures as well as temperatures have been calculated for investigated alloys. In these investigations, thermodynamics parameters for the above-said alloys have been evaluated for a wide range of temperatures i.e. from $0-1100 \mathrm{~K}$ at $\mathrm{P}=0 \mathrm{GPa}$ 
as shown in Figs. 15-20. The variation in volumes with the variation in temperature at $\mathrm{P}=0 \mathrm{GPa}$ is shown in Fig. 15. From Fig. 15 it is can be seen that the value of the volumes increases with the increase in temperature for each concentration of $\mathrm{x}$ it because crystal volume increases with increasing temperature. From Fig. 15, we have seen that the values of the volume increase in the order $\mathrm{GaN}_{0.75} \mathrm{As}_{0.25}<\mathrm{GaN}_{0.5} \mathrm{As}_{0.5}<\mathrm{GaN}_{0.25} \mathrm{As}_{0.75}<\mathrm{GaN}<\mathrm{GaAs}$. Hence, volumes of the simulated crystal structures at $\mathrm{P}=0 \mathrm{GPa}$ and temperature $\mathrm{T}=300 \mathrm{~K}$ at compositions $\mathrm{x}=0,0.25,0.5,0.75$ and 1.00 are $313.75(\mathrm{Bohr})^{3}, 283.13(\mathrm{Bohr})^{3}, 244.66$

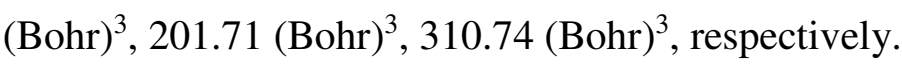

Fig. 16 shows the variation of bulk modulus $B$ values, at fixed pressure $\mathrm{P}=0 \mathrm{GPa}$ and different temperatures. We observe that the values of the bulk modulus are decreasing with rising temperatures at a fixed pressure $(\mathrm{P}=0 \mathrm{GPa})$. Hence the sequence of the increase in bulk modulus is as GaAs $<\mathrm{GaN}_{0.25} \mathrm{As}_{0.75}<\mathrm{GaN}_{0.5} \mathrm{As}_{0.5}<\mathrm{GaN}_{0.75} \mathrm{As}_{0.25}<\mathrm{GaN}$. The values of the simulated crystalline alloys samples at fixed pressure $\mathrm{P}=0 \mathrm{GPa}$ and temperature $\mathrm{T}=300 \mathrm{~K}$ are in an order of $59.81 \mathrm{GPa}, 69.61 \mathrm{GPa}, 82.40 \mathrm{GPa}, 118.29 \mathrm{GPa}$, and $183.19 \mathrm{GPa}$ respectively for the $\mathrm{x}=0,0.25,0.5,0.75$ and 1.00 , showing that investigated alloys are becoming harder and harder with decreasing temperature and increasing pressure.

Debye temperature $\left(\theta_{D}\right)$ is an important parameter of a solid which depicts the temperature of solid material at which it gets a maximum number of possible vibrational modes and hardness. Fig. 17 shows the various values of the Debye temperature when the temperature of solid alloys is increased while keeping their constant pressure at $\mathrm{P}=0 \mathrm{GPa}$, one can see that $\Theta_{\mathrm{D}}$ is decreasing with the increase in temperature at constant pressure. At zero temperature and pressure, our results of the $\theta_{\mathrm{D}}$ are $323.21 \mathrm{~K}<402.68 \mathrm{~K}<460.45 \mathrm{~K}<549.37 \mathrm{~K}<706.22 \mathrm{~K}$ whereas at temperature $300 \mathrm{~K}$ and pressure $0 \mathrm{GPa}$ are $312.48 \mathrm{~K}<387.94 \mathrm{~K}<445.44 \mathrm{~K}<$ $536.60 \mathrm{~K}<702.49 \mathrm{~K}$ for $\mathrm{x}=1 ; 0.75 ; 0.5 ; 0.25$ and 0 respectively.

Investigation of the heat capacity and entropy is necessary for many applications, for example, at constant volume, their knowledge of the vibratory properties of a crystalline material is necessary. Fig. 18 shows our calculated results of the heat capacity as a function of temperature and fixed pressure $(0 \mathrm{GPa})$ for all the investigated concentrations of the $\mathrm{GaN}_{\mathrm{x}} \mathrm{As} \mathrm{s}_{1-}$ $x$ alloys. From Fig. 18, it can be seen that the $C_{V}$ values for the compositions $x=0.25,0.5$, and 0.75 are greater than that of $x=0$ and $x=1$. However, our computed results of $C_{V}$ shown in Fig. 18 follow the Debye $\mathrm{T}^{3}$ law [124] whereas, at further higher temperatures, results follow to Dulong-Petit limit described in the literature [125]. For the ternary mixed alloys, the values for $\mathrm{GaN}_{0.25} \mathrm{As}_{0.75}, \mathrm{GaN}_{0.5} \mathrm{As}_{0.5}$, and $\mathrm{GaN}_{0.75} \mathrm{As}_{0.25}$ are $74.474 \mathrm{~J} / \mathrm{mol} \times \mathrm{K}$ and for GaAs and $\mathrm{GaN}$ are $49.796 \mathrm{~J} / \mathrm{mol} \times \mathrm{K}$. Our results for $\mathrm{GaN}$ are in good agreement with Achour et al. (49.90 
$\mathrm{J} / \mathrm{mol} \times \mathrm{K})[6 \mathbf{6 6}$. Our calculated values of specific heat at ambient conditions $\mathrm{T}=300 \mathrm{~K}$ and $\mathrm{P}=$ $0 \mathrm{GPa}$ are $38.496 \mathrm{~J} / \mathrm{mol} \times \mathrm{K}($ for $\mathrm{x}=1)<47.282 \mathrm{~J} / \mathrm{mol} \times \mathrm{K}($ for $\mathrm{x}=0$ ) $<64.104 \mathrm{~J} / \mathrm{mol} \times \mathrm{K}$ (for $\mathrm{x}=0.75)<67.189 \mathrm{~J} / \mathrm{mol} \times \mathrm{K}($ for $\mathrm{x}=0.5)<68.929 \mathrm{~J} / \mathrm{mol} \times \mathrm{K}($ for $\mathrm{x}=0.25)$.

Our obtained results for entropy $\mathrm{S}$ with respect to varying temperature and at fixed pressure $\mathrm{P}$ $=0 \mathrm{GPa}$ are displayed in Fig. 19. From Fig. 19, one can see that entropy results for the ternary alloys for all compositions of $\mathrm{x}$ are increasing non-linearly with increasing temperature. The number of phonon modes is decreasing but this effect is reversed in the case of rising temperature at a fixed pressure. Our simulated results for the entropy at $\mathrm{T}=300 \mathrm{~K}$ and $\mathrm{P}=0 \mathrm{GPa}$ are $30.306 \mathrm{~J} / \mathrm{mol} \times \mathrm{K}<65.81 \mathrm{~J} / \mathrm{mol} \times \mathrm{K}<61.927 \mathrm{~J} / \mathrm{mol} \times \mathrm{K}<74.164 \mathrm{~J} / \mathrm{mol} \times \mathrm{K}<$ $83.576 \mathrm{~J} / \mathrm{mol} \times \mathrm{K}$ for $\mathrm{x}=1,0,0.75,0.5$ and 0.25 respectively.

The coefficients of the thermal expansion describe an expansion of a solid with temperature.

Fig. 20 displays the variation of the thermal expansion coefficient of the $\mathrm{GaN}_{\mathrm{x}} \mathrm{As} \mathrm{s}_{1-\mathrm{x}}$ alloys with the temperature at a fixed pressure. From Fig. 20, one can see that the value of the thermal expansion first increases sharply with temperature up to 200K. However, when T increases beyond $200 \mathrm{~K}$, it increases slowly and approximately becomes linear at high temperatures. For comparison, no results in the literature are reported yet.

\section{Conclusions}

In conclusion, we used the FP-L(APW+lo) method framed within the DFT to investigating phase stability, thermal, optical, and electronic properties of the mixed ternary alloys $\mathrm{GaN}_{\mathrm{x}} \mathrm{As}_{1-\mathrm{x}}$. The $\mathrm{B} 3$ phase was found the most stable one for $\mathrm{x}=0 ; 0.25 ; 0.5$ and 0.75 concentrations whereas for $\mathrm{x}=1$, the most stable phase was found to be $\mathrm{B} 4$. The band structures obtained at the level of the $\mathrm{mBJ}$ approach for all compositions of mixed alloys showed a direct bandgap nature at $\Gamma-\Gamma$ point in the Brillouin zone. The results obtained for investigated compositions of the $\mathrm{GaN}_{\mathrm{x}} \mathrm{As}_{1-\mathrm{x}}$ alloys showed a good agreement with the reported results in the literature. The results obtained, for temperature range of $0-1100 \mathrm{~K}$ and zero pressure, by employing the approach based on the "quasi-harmonic Debye model" showed that our results obeyed the Dulong-Petit limit. Furthermore, the analysis of our obtained results of the electronic and optical properties highlighted that the $\mathrm{GaN}_{\mathrm{x}} \mathrm{As}_{1-\mathrm{x}}$ alloys could be promising materials for their applications in optoelectronic devices. To our knowledge, this is first study regarding thermal and optical properties of $\mathrm{GaN}_{\mathrm{x}} \mathrm{As}_{1-\mathrm{x}}$ alloys by $\mathrm{mBJ}$ approximation, henceforth this study could be a milestone for further investigations to exploit their potential for technological applications. 


\section{Acknowledgment}

The authors acknowledge the financial Support of the General Direction of Scientific Research and Technological Development (DGRSDT).

The author (Bakhtiar Ul Haq) extends his appreciation to the Deanship of Scientific Research at King Khalid University for funding his work through Research Groups Program under Grant No. R.G.P. 2/126/42.

\section{References}

[1] J.W. Ager III, W. Walukiewicz, Semicond. Sci. Technol., 17 (2002) 741.

[2] J. Buckeridge, S. O’Halloran, S. Fahy, Solid State Commun., 150 (2010) 1967-1970.

[3] L. Bellaiche, S. H. Wei, A. Zunger, Phys. Rev. B, 54 (1996) 17568.

[4] S.G. Spruytte, C.W. Coldren, J.S. Harris, W. Wampler, P. Krispin, K. Ploog, M.C. Larson, J. Appl. Phys., 89 (2001) 4401.

[5] M. Kondow, K. Uomi, A. Niwa, T. Kitatani, S. Watahiki, Y. Yazawa, Jpn. J. Appl. Phys., 35 (1996) 1273.

[6] I. A. Buyanova, W. M. Chen, G. Pozina, J. P. Bergman, and B. Monemar, H. P. Xin, C. W. Tu, Appl. Phys. Lett., 75 (1999) 501.

[7] J. S. Harris Jr., Semicond. Sci. Technol., 17 (2002) 880.

[8] M. Kondow, T. Kitatani, IEE Proc., J. Optoelectron., 150 (2003) 9.

[9] S. J. Barker, R. S. Williams, C. P.A. Mulcahy, M. J. Steer, M. Hopkinson, M.J. Ashwin, R.C. Newman, P.N. Stavrinou, G. Parry, T.S. Jones, Thin Solid Films, 515 (2007) 44304434.

[10] S. Ahmed, J. Lin, A. Haq, B. Sealy, Nucl. Instrum. Methods Phys. Res., B 237 (2005) $102-106$.

[11] G. Li, W. Han, Y. Luo, D. Han, C. Ji, in: Proceedings of 4th International Conference on Sol. Stat. Int. Cir. Tech. (1995) 399.

[12] M. Kondow, K. Uomi, T. Kitatani, S. Watahiki, Y. Yazawa, J. Cryst. Growth, 164 (1996) 175.

[13] S.B. Zhang, S.H. Wei, Phys. Rev. Lett., 86 (2001) 1789.

[14] W. G. Bi and C. W. Tu, Appl. Phys. Lett., 70 (1997) 1608. 
[15] K. Kawamoto, T. Suda, T. Akiyama, K. Nakamura, T. Ito, Appl. Surf. Sci., 244 (2005) $182-185$.

[16] Q. Gao, P.K. Deenapanray, H.H. Tan, C. Jagadish, Appl. Phys. Lett., 83 (2003) 3386.

[17] O. Zsebök, J. V. Thordson, L. Ilver, T. G. Andersson, NanoStruct. Mater., 12 (1999) 425-428.

[18] I. A. Buyanova, M. Izadifard, W. M. Chen, A. Polimeni, M. Capizzi, H. P. Xin, C. W. Tu, Appl. Phys. Lett., 82 (2003) 3662.

[19] W.K. Cheah, W.J. Fan, S. Wicaksono, S.F. Yoon, K.H. Tan, J. Cryst. Growth, 254 (2003) 305-309.

[20] W.J. Fan, S.F. Yoon, W.K. Cheah, W.K. Loke, T.K. Ng, S.Z. Wang, R. Liu, A. Wee, J. Cryst. Growth, 268 (2004) 470-474.

[21] E.C. Young, S. Tixier, T. Tiedje, J. Cryst. Growth, 279 (2005) 316-320.

[22] W.K. Loke, S.F. Yoon, T.K. Ng, S.Z. Wang, W.J. Fan, J. Cryst. Growth, 243 (2002) $427-431$.

[23] J. A. Cardona-Bedoya, A. Cruz-Orea, J. G. Mendoza-Alvarez, M. L.Gomez-Herrera, M. H. Farias, J.A. Diaz, Appl. Surf. Sci., 238 (2004) 147-150.

[24] Y.G. Hong, C.W. Tu, J. Cryst. Growth, 242 (2002) 29-34.

[25] P. N. Hai, W. M. Chen, I. A. Buyanova, H. P. Xin, C. W. Tu, Appl. Phys. Lett., 77 (2000) 1843.

[26] P. Pichanusakorn, Y. J. Kuang, C. J. Patel, C. W. Tu, P. R. Bandaru, Appl. Phys. Lett., 99 (2011) 072114.

[27] J. Jasinski, K.M. Yu, W. Walukiewicz, Z. Liliental-Weber, J. Washburn, Physica B 308310 (2001) 874-876.

[28] R. J. Potter, N. Balkan, H. Carrère, A. Arnoult, E. Bedel, X. Marie, Appl. Phys. Lett., 82 (2003) 3400 .

[29] K.M. Yu, J. Wu, W. Walukiewicz, W. Shan, J.W. Beeman, D.E. Mars, D.R Chamberlin, M.A. Scarpulla, O. D. Dubon, M.C. Ridgway, J.F. Geisz, Physica B, 340-342 (2003) 389393.

[30] K.M. Yu, W. Walukiewicz, J. Wu, D.E. Mars, D.R. Chamberlin, M.A. Scarlupa, O.D.Dubon, J.F. Geisz, Nat. Mater., 1 (2002) 185.

[31] J. Wu, K.M. Yu, W. Walukiewicz, G. He, E.E. Haller, D.E. Mars, D.R. Chamberlin, Phys. Rev. B, 68 (2003) 195202.

[32] K.M. Yu, W. Walukiewicz, W.S.J. Wu, J.W. Beeman, M.A. Scarpula, O.D. Dubon, M.C. Ridgway, D.E. Mars, D.R. Chamberlin, Appl. Phys. Lett., 83 (2003) 2844. 
[33] H. Baaziz, Z. Charifi, A. H. Reshak, B. Hamad, Y. Al-Douri, Appl Phys A, 106 (2012) 687-696.

[34] M. Aslan, Battal G. Yalcin, International Journal of Physical Research, 4 (2016) 6-11.

[35] M. I. Ziane, Z. Bensaad, T. Ouahrani, B. Labdelli, H. Ben Nacer, H. Abid, Mater. Sci. Semicond. Process. (4) (2013) 1138-1147.

[36] N. Bouarissa, S.A. Siddiqui, M. Boucenna, M.A. Khan, Optik, 131(2017) 317-322.

[37] T. Suda, Y. Kangawa, K.Nakamura, T.Ito, J. Cryst. Growth, 258 (2003) 277-282.

[38] T. Ito, T. Suda, T. Akiyama, K. Nakamura, Appl. Surf. Sci., 244 (2005) 170-173.

[39] A. Lindsay, E.P.O’Reilly, Solid State Commun., 118 (2001) 313-317.

[40] A.H. Reshak, Z. Charifi, H. Baaziz, Solar Energy, 90 (2013) 134-143.

[41] M. Oukli, N. Mehnane, H.Abid, Chin. J. Phys., 54 (2016) 60-68.

[42] A. Lindsay, E.P. O’Reilly, Physica E, 21 (2004) 901 - 906.

[43] A.H. Reshak, J. Alloys Compd., 589 (2014) 213-217.

[44] G. Stenuit, S. Fahy, J. Phys. Chem. Solids, 70 (2009) 769-777.

[45] S. Cottenier, DFT and the family of (L) APW-methods: a step-by-step introduction, K.U. Leuven (http: / www. wien2k. at / reg_user / textbooks),(2002).

[46] O.K. Andersen, Phys. Rev. B, 42 (1975) 3060.

[47] P. Blaha, K. Schwarz, G. K.H. Madsen, D. Kvasnicka, J. Luitz, WIEN2k, An Augmented Plane Wave Plus Local Orbitals Program for Calculating Crystal Properties (Vienna University of Technology, Vienna, Austria,2001).

[48] Z. Wu, R. E. Cohen, Phys. Rev. B, 73 (2006) 235116.

[49] F. Tran, P. Blaha, Phys. Rev. Lett., 102 (2009) 226401.

[50] W. Wettling, J. Windscheif, Solid State Commun., 50 (1984) 33.

[51] N. E. Christensen, Electronic structure calculations for semiconductors under pressure, in: T. Suski, W. Paul (Eds.), High Pressure in Semiconductor Physics I, Academic Press, New York, 1998.

[52] S. Minomura, H.G. Drickamer, J. Phys. Chem. Solids Pergamon Press, 23 (1962) 451456.

[53] S.B. Zhang, M.L. Cohen, Phys. Rev. B, 35 (1987) I.

[54] E. Güler, M. Güler, Mater. Res., 17 (5) (2014) 1268-1272.

[55] R. K. Singh, S. Singh, Phys. Rev. B, 39 (1989).

[56] D. Varshney, G. Joshi, M. Varshney, S. Shriya, J. Alloys Compd., 495 (2010) 23-32.

[57] S. Gagui, S. Ghemid, H. Meradji, B. Zaidi, B. Amimour, S.A. Tahir, R. Ahmed, B. Chouial, B. Hadjoudja, A.K. Kushwaha, Optik, 219 (2020) 165253. 
[58] S. Touam, R. Belghit, R. Mahdjoubi, Y. Megdoud, H. Meradji, M.S. Khan, R. Ahmed, R. Khenata, S. Ghemid, D.P. Rai, Y.A. Douri, Bull. Mater.Sci., 43 (2020) 22.

[59] M. P. Halshal, P. Harmer, P. J. Parbrook, S. J. Henley, Phys. Rev. B, 69 (2004) 235207.

[60] M. Ueno, M. Yoshida, A. Onodera, O. Shimomura, K. Takemura, Phys. Rev. B, 49 (1994) 14.

[61] X. Sun, Q. Chen, Y. Chu, Physica B, 368 (2005) 243-250.

[62] S. Zerroug, F. Ali Sahraoui, N. Bouarissa, J. Appl. Phys., 103 (2008) 063510.

[63] J. Serrano, A. Rubio, Phys. Rev. B, 62 (2000) 16612-16623.

[64] M. A. Jafar, A. I. Al-Sharif, A. Qteish, Solid State Commun. 116 (2000) 389.

[65] S. Saib, N. Bouarissa, Physica B, 387 (2007) 377-382.

[66] H. Achour, S. L. Fasla, F. Mana, Physics Procedia, 55 (2014) 17-23.

[67] O. Arbouche, B. Belgoumène, B. Soudini, M. Driz, Comput. Mater. Sci., 47 (2009) $432-$ 438.

[68] H. Xia, Q. Xia, A.L. Ruoff, Phys. Rev. B, 47 (1993) 12925.

[69] J. Cai, N. Chen, Phys. Rev. B, 75 (2007)134109.

[70] F.D. Murnaghan, Proc. Natl. Acad. Sci. U.S.A., 30 (1944) 244.

[71] R.C. Weast, Handbook of Chemistry and Physics (CRC, Boca Raton, 1981).

[72] S. Adachi, J. Appl. Phys., 58 (1985) R1.

[73] M. Hanfland, K. Syssen, N.E. Christensen, J. Phys., 45 (1984).

[74] K.H. Hellwege, O. Madelung, Landolt-Bornstein. Semiconductors: Physics of Group IV Elements and III-V Alloys, New Series, Group III, (1982) 17.

[75] P.K. Lam, M.L. Cohen, G. Martinez, Phys. Rev. B, 35 (1987) 9190.

[76] M. I. Ziane, Z. Bensaad, B. Labdelli, H. Bennacer, Sensors \& Transducers, 27 ( 2014) 374-384.

[77] R. Moussa, A. Abdiche, B. Abbar, M. Guemou, R. Riane, G. Murtaza, S. B. Omran, R. Khenata, F. Soyalp, J. Electron. Mater., 44(2015) 4684-4699.

[78] S. Menezla, A. Kadri, K. Zitouni, A. Djelal, M. Djermouni, A. Hallouche, A. Zaoui, Superlattices Microstruct., 88 (2015)18-31.

[79] A. Abdiche, H. Abid, R. Riane, A. Bouaza, Physica B, 405 (2010) 2311-2316.

[80] Y. Al-Douri, A. H. Reshak, Appl Phys A, 104 (2011) 1159-1167.

[81] M. Baublitz Jr, A. L. Ruoff, J. Appl. Phys., 53 (1982) 6179.

[82] T. Lei, T.D. Moustaka, R.J. Graham, Y. He, S.J. Berkowitz, J. Appl. Phys., 71 (1992) 4933.

[83] M. Aslan, B. G. Yalçin, M. Ustundag, J. Alloys. Compd., 519 (2012) 55-59. 
[84] M. I. Ziane, Z. Bensaad, T. Ouahrani, H. Bennacer, Mat. Sci. Semicon. Proc., 30 (2015) 181-196.

[85] T. Lei, M. Franciulli, R. J. Molnar, T. D. Moustakas, R. J. Graham, J. Scanlon, Appl. Phys. Lett., 59 (1991) 944.

[86] A. Sheleg, V. Savastenko, Inorg. Mater., 15 (1979) 1257.

[87] A. F. Wright, J. S. Nelson, Phys. Rev. B: Condens. Matter, 50 (4) (1994) 2159-2165.

[88] A. F. Wright, J. S. Nelson, Phys. Rev. B, 51 (12) (1995) 7866-7869.

[89] D. Vogel, P. Kruger, J. Pollmann, Phys. Rev. B, 55(1997) 12836.

[90] M.E. Sherwin, T.J. Drummond, J. Appl. Phys., 69 (1991) 8423.

[91] B. U. Haq , R. Ahmed, A. Shaari, F. E. Haj Hassan, M. B. Kanoun, S. G.Said, Sol. Energy, 107 (2014) 543-552.

[92] A. Abdiche, A. Oualdine, M. Guemou, R. Khenata, F. Soyalp, R. Ahmed, S.A. Tahir, S.

B. Omran, Mater. Today Commun., 26 (2021) 101752.

[93] M. B. Kanoun, A. E. Merad, J. Cibert , H. Aourag, G. Merad, J. Alloys Compd., 366 (2004) 86-93.

[94] L. Liu, J. H. Edgar, Mater. Sci. Eng.R Rep, 37(3) (2002) 61-127.

[95] H. Schulz, K. Thiemann, Solid State Commun., 23 (11) (1977) 815-819.

[96] V. Gavrilenko, R.Wu, Phys. Rev. B, 61 (4) (2000) 2632.

[97] S. Sakai, Y. Ueta, Y. Terauchi, Jpn. J. Appl. Phys., 32 (1993) 4413.

[98] A. Rubio, M.L. Cohen, Phys. Rev. B, 51 (1995) 4343.

[99] J. Neugebauer, C.G. Van deWalle, Phys. Rev. B, 51 (1995) 10568.

[100] S. H. Wei, A. Zunger, Phys. Rev. Lett., 76 (1996) 664.

[101] L. Ballaiche, S.-H.Wei, A. Zunger, Phys. Rev. B, 54 (1996) 17568.

[102] J. A. Van Vechten, Phys. Rev., 182 (1969) 891.

[103] M.G. Brik, J. Phys. Chem. Solids, 71 (2010) 1435.

[104] A. K. Singh, D. Chandra, S. Kattayat, S. Kumar, P. A. Alvi, A. Rathi, Semiconductors, 53(2019) 1584-1592.

[105] O. Nemiri, F. Oumelaz, A. Boumaza, S. Ghemid, H. Meradji, W.K. Ahmed, R. Khenata, X. Wang, J. Mol. Graphics Modell., 92 (2019) 140-146.

[106] R. Moussa, A. Abdiche, R. Khenata, R. Ahmed, S. A. Tahir, S. B. Omran, A. Bouhemadou, Mater. Sci. Semicond. Process., 126 (2021) 105642.

[107] S. Adachi, Wiley, England, 373 (2005).

[108] B. Monemar, Phys. Rev.B, 10 (2) (1974) 676-681. 
[109] C. H. Su, W. Palosz, S. Zhu, S. L. Lehoczky, I. Grzegory, P. Perlin, T. Suski, J. Cryst. Growth, 235 (2002) 111-114.

[110] V. Y. Davydov, A. Klochikhin, R. Seisyan, V.Emtsev, S. Ivanov, F. Bechstedt, J. Furthmüller, H. Harima, A. Mudryi, J. Aderhold, Phys. Status Solidi B, 229 (3)(2002) r1-r3.

[111] P. Rinke, M. Scheffler, A. Qteish, M. Winkelnkemper, D. Bimberg, J. Neugebauer, Appl. Phys.Lett., 89 (2006) 161919.

[112] G. Harbeke, In Optical properties of Solids, in: F. Abelès (Ed.), North-Holland, Amsterdam, 1972.

[113] P. J. L. Hervé, L. K. J. Vandamme, Infrared Phys. Technol., 35 (1994) 609.

[114] N. M. Ravindra, S. Auluck, V. K. Srivastava, Phys. Status Solidi B, 93 (1979) K155.

[115] T. S. Moss, Proc. Phys. Soc., London B, 63 (1950) 167.

[116] A. Alahmary, N. Bouarissa, A. Kamli, Physica B, 403 (2008) 1990.

[117] M. Othman, E. Kasap, N. Korozlu, J. Alloys. Compd., 496 (2010) 226-233.

[118] L. Marton, Rev. Mod. Phys., 28 (1956) 172.

[119] F. Pradal, C. Gout, D. Fabre, J. Phys., 26 (1965) 372-384.

[120] M. A. Blanco, E. Francisco, V. Luaňa, Comput. Phys. Commun., 158 (2004) 57.

[121] M. A. Blanco, A. Martín Pendás, E. Francisco, J. M. Recio, R. Franco, J. Mol. Struct. Theochem, 368 (1996) 245.

[122] M. Florez, J. M. Recio, E. Francisco, M. A. Blanco, A. Martín Pendás, Phys. Rev. B, 66 (2002) 144112.

[123] J. P. Poirier, Introduction to the Physics of the Earth's Interior, Cambridge University Press, Oxford vol. 39.

[124] P. Debye, Ann. Phys., 344 (1912) 789.

[125] A.T. Petit, P.L. Dulong, Ann. Chem. Phys., 10 (1819) 395. 
Table 1 Transition pressure $\mathrm{P}_{\mathrm{t}}$ for binary compounds and their mixed alloys $\mathrm{GaN}_{\mathrm{x}} \mathrm{As}_{1-\mathrm{x}}$ using WC-GGA approximation compared to previous experimental and other theoretical studies.

\begin{tabular}{|c|c|c|c|c|}
\hline \multirow[t]{2}{*}{$\mathrm{GaN}_{\mathrm{x}} \mathrm{As}_{1-\mathrm{x}}$} & \multirow[t]{2}{*}{ Transition } & \multicolumn{3}{|c|}{ Transition pressure $\mathrm{P}_{\mathrm{t}}(\mathrm{GPa})$} \\
\hline & & This work & Expt. & Other works \\
\hline \multirow[t]{5}{*}{$\mathrm{x}=0$} & $\mathrm{~B} 3 \rightarrow \mathrm{B} 1$ & 12.270 & $16.6^{\mathrm{a}}, 24.5-25^{\mathrm{b}}$ & $16^{\mathrm{c}}, 17^{\mathrm{d}, \mathrm{e}, \mathrm{f}}, 12.00^{\mathrm{g}}, 11.76^{\mathrm{h}}$ \\
\hline & $\mathrm{B} 3 \rightarrow \mathrm{B} 2$ & 17.590 & & \\
\hline & $\mathrm{B} 4 \rightarrow \mathrm{B} 1$ & 13.473 & & \\
\hline & $\mathrm{B} 4 \rightarrow \mathrm{B} 2$ & 18.829 & & \\
\hline & $\mathrm{B} 1 \rightarrow \mathrm{B} 2$ & 46.719 & & \\
\hline \multirow[t]{5}{*}{$\mathrm{x}=0.25$} & $\mathrm{~B} 3 \rightarrow \mathrm{B} 1$ & 15.746 & & \\
\hline & $\mathrm{B} 3 \rightarrow \mathrm{B} 2$ & 25.596 & & \\
\hline & $\mathrm{B} 4 \rightarrow \mathrm{B} 1$ & 12.725 & & \\
\hline & $\mathrm{B} 4 \rightarrow \mathrm{B} 2$ & 25.784 & & \\
\hline & $\mathrm{B} 1 \rightarrow \mathrm{B} 2$ & 103.230 & & \\
\hline \multirow[t]{6}{*}{$x=0.5$} & $\mathrm{~B} 3 \rightarrow \mathrm{B} 4$ & 37.418 & & \\
\hline & $\mathrm{B} 3 \rightarrow \mathrm{B} 1$ & 21.292 & & \\
\hline & $\mathrm{B} 3 \rightarrow \mathrm{B} 2$ & 41.759 & & \\
\hline & $\mathrm{B} 4 \rightarrow \mathrm{B} 1$ & 17.401 & & \\
\hline & $\mathrm{B} 4 \rightarrow \mathrm{B} 2$ & 37.418 & & \\
\hline & $\mathrm{B} 1 \rightarrow \mathrm{B} 2$ & 144.879 & & \\
\hline \multirow[t]{5}{*}{$\mathrm{x}=0.75$} & $\mathrm{~B} 3 \rightarrow \mathrm{B} 1$ & 28.179 & & \\
\hline & $\mathrm{B} 3 \rightarrow \mathrm{B} 2$ & 91.418 & & \\
\hline & $\mathrm{B} 4 \rightarrow \mathrm{B} 1$ & 27.614 & & \\
\hline & $\mathrm{B} 4 \rightarrow \mathrm{B} 2$ & 85.100 & & \\
\hline & $\mathrm{B} 1 \rightarrow \mathrm{B} 2$ & & & \\
\hline \multirow[t]{4}{*}{$\mathrm{x}=1$} & $\mathrm{~B} 3 \rightarrow \mathrm{B} 1$ & 43.958 & $42^{\mathrm{i}}, 52.2^{\mathrm{j}}$ & $\begin{array}{l}44^{\mathrm{k}}, 42.98^{\mathrm{l}}, 42.1^{\mathrm{m}}, 41^{\mathrm{f}}, 40.80^{\mathrm{n}}, 37.07^{\mathrm{o}}, \\
29.1^{\mathrm{p}}, 45.15^{\mathrm{q}}\end{array}$ \\
\hline & $\mathrm{B} 3 \rightarrow \mathrm{B} 2$ & 200.202 & & \\
\hline & $\mathrm{B} 4 \rightarrow \mathrm{B} 1$ & 48.345 & $37^{\mathrm{r}}, 52.2^{\mathrm{j}}$ & $42.9^{\mathrm{m}}, 36.5^{\mathrm{p}}, 44.5^{\mathrm{s}}$ \\
\hline & $\mathrm{B} 4 \rightarrow \mathrm{B} 2$ & 204.251 & & \\
\hline
\end{tabular}

${ }^{\mathrm{a}}$ Ref. [51].

${ }^{b}$ Ref. [52].

${ }^{\mathrm{c}}$ Ref. [53].

${ }^{\mathrm{d}}$ Ref. [54].

${ }^{\mathrm{e}}$ Ref. [55].

${ }^{\mathrm{f}}$ Ref. [56]. 
${ }^{\mathrm{g}}$ Ref. [57].

${ }^{\mathrm{h}}$ Ref. [58].

${ }^{\mathrm{i}}$ Ref. [59].

${ }^{j}$ Ref. [60].

${ }^{\mathrm{k}}$ Ref. [61].

${ }^{1}$ Ref. [62].

${ }^{\mathrm{m}}$ Ref. [63].

${ }^{\mathrm{n}}$ Ref. [64].

${ }^{\circ}$ Ref. [65].

${ }^{\mathrm{p}}$ Ref. [66].

${ }^{\mathrm{q}}$ Ref. [67].

${ }^{\mathrm{r}}$ Ref. [68].

${ }^{\mathrm{s}}$ Ref. [69]. 
Table 2: Calculated lattice constant a $(\AA)$, c/a ratio, bulk modulus $\mathrm{B}(\mathrm{GPa})$ and pressure derivation of bulk modulus B'(GPa) using WC-GGA approximations for $\mathrm{GaN}_{\mathrm{x}} \mathrm{As}_{1-\mathrm{x}}$ alloys compared with experimental results and other theoretical works.

\begin{tabular}{|c|c|c|c|c|c|}
\hline $\mathbf{G a N}_{\mathbf{x}} \mathbf{A s 1 - x}$ & $\mathbf{a}$ & $\mathbf{c}$ & $\mathbf{c} / \mathbf{a}$ & B & B' \\
\hline \multicolumn{6}{|l|}{ GaAs } \\
\hline $\mathrm{NaCl}$ (B1) This work & 5.322 & & & 81.179 & 4.870 \\
\hline $\mathrm{CsCl}$ (B2) This work & 3.321 & & & 73.840 & 3.958 \\
\hline ZB (B3) This work & 5.667 & & & 69.186 & 4.856 \\
\hline Experiment & $\begin{array}{l}5.653^{\mathrm{a}, \mathrm{b}}, 5.65^{\mathrm{c}} \\
5.64^{\mathrm{d}}\end{array}$ & & & $\begin{array}{l}75.5^{\mathrm{b}}, 77.00^{\mathrm{d}}, \\
74.8^{\mathrm{e}}\end{array}$ & \\
\hline Theory & $\begin{array}{l}5.664^{\mathrm{f}}, 5.668^{\mathrm{g}} \\
5.665^{\mathrm{h}}, 5.660^{\mathrm{i}} \\
5.75^{\mathrm{j}, \mathrm{k}}, 5.75^{\mathrm{l}}, 5.73^{\mathrm{m}} \\
5.53^{\mathrm{n}}\end{array}$ & & & $\begin{array}{l}69.711^{\mathrm{f}}, \\
69.674^{\mathrm{h}}, \\
69.523^{\mathrm{g}}, 68.68^{\mathrm{i}}, \\
61.32^{\mathrm{j}}, 61.00^{\mathrm{l}}, \\
60.83^{\mathrm{m}}, 60.622^{\mathrm{k}}\end{array}$ & $\begin{array}{l}4.343^{\mathrm{h}}, 4.563^{\mathrm{k}}, \\
4.54^{\mathrm{i}}, 5.15^{1}, \\
4.60^{\mathrm{m}}\end{array}$ \\
\hline Wurtzite (B4) This work & 4.003 & 6.556 & 1.63 & 69.147 & 4.619 \\
\hline \multicolumn{6}{|l|}{$\mathbf{G a N}_{0.25} \mathbf{A s}_{0.75}$} \\
\hline $\mathrm{NaCl}(\mathrm{B} 1)$ This work & 5.130 & & & 91.106 & 4.787 \\
\hline $\mathrm{CsCl}$ (B2) This work & 3.206 & & & 80.831 & 4.856 \\
\hline ZB (B3) This work & 5.462 & & & 78.374 & 4.555 \\
\hline Theory & $5.451^{\mathrm{f}}, 5.55^{\mathrm{j}}$ & & & $76.251^{f}, 62.9^{j}$ & \\
\hline Wurtzite (B4) This work & 3.868 & 6.298 & 1.62 & 77.537 & 4.639 \\
\hline \multicolumn{6}{|l|}{$\mathbf{G a N}_{0.5} \mathbf{A s}_{0.5}$} \\
\hline $\mathrm{NaCl}(\mathrm{B} 1)$ This work & 4.889 & & & 111.229 & 4.803 \\
\hline $\mathrm{CsCl}$ (B2) This work & 3.074 & & & 94.042 & 4.547 \\
\hline ZB (B3) This work & 5.203 & & & 94.955 & 4.740 \\
\hline Theory & $5.20^{\mathrm{f}}, 5.27^{\mathrm{j}}, 5.28^{\mathrm{n}}$ & & & $91.274^{\mathrm{f}}, 88.5^{\mathrm{j}}$ & \\
\hline Wurtzite (B4) This work & 3.686 & 5.997 & 1.62 & 94.670 & 6.363 \\
\hline \multicolumn{6}{|l|}{$\mathbf{G a N}_{0.75} \mathbf{A s}_{0.25}$} \\
\hline $\mathrm{NaCl}$ (B1) This work & 4.597 & & & 145.590 & 4.474 \\
\hline $\mathrm{CsCl}$ (B2) This work & 2.912 & & & 117.500 & 4.741 \\
\hline ZB (B3) This work & 4.883 & & & 126.153 & 4.575 \\
\hline Theory & $4.889^{\mathrm{f}}, 4.94^{\mathrm{j}}$ & & & $\begin{array}{l}124.201^{\mathrm{f}}, \\
111.12^{\mathrm{j}}\end{array}$ & \\
\hline Wurtzite (B4) This work & 3.471 & 5.609 & 1.61 & & \\
\hline \multicolumn{6}{|l|}{ GaN } \\
\hline $\mathrm{NaCl}$ (B1) This work & 4.23 & & & 231.034 & 4.638 \\
\hline Theory & $\begin{array}{l}4.184^{\circ}, 4.26^{\mathrm{p}}, \\
4.27^{\mathrm{q}}, 4.225^{\mathrm{r}}\end{array}$ & & & $\begin{array}{l}233.313^{\mathrm{o}} \\
224.70^{\mathrm{p}} \\
195^{\mathrm{q}} \\
240^{\mathrm{r}}\end{array}$ & $\begin{array}{l}4.531^{\mathrm{o}} \\
3.99^{\mathrm{p}} \\
4.81^{\mathrm{q}} \\
4.5^{\mathrm{r}}\end{array}$ \\
\hline $\mathrm{CsCl}$ (B2) This work & 2.713 & & & 161.635 & 4.456 \\
\hline ZB (B3) This work & 4.504 & & & 189.488 & 4.461 \\
\hline Experiment & $\begin{array}{l}4.50^{\mathrm{s}, \mathrm{t}, \mathrm{u}} \\
4.45^{\mathrm{v}} \\
4.49^{\mathrm{w}}\end{array}$ & & & $\begin{array}{l}190^{r, a a, b b} \\
195^{x} \\
173-200^{y-z}\end{array}$ & $2.66-4.6^{y-z}$ \\
\hline Theory & $\begin{array}{l}.508^{\mathrm{f}}, 4.56^{\mathrm{j}}, \\
4.55^{\mathrm{n}, \mathrm{cc}}, 4.508^{\mathrm{h}, \mathrm{dd}}, \\
4.473^{\mathrm{ee}} \\
4.497^{\mathrm{r}}\end{array}$ & & & $\begin{array}{l}190.932^{\mathrm{f}}, \\
172.2^{\mathrm{j}}, \\
193.214^{\mathrm{h}} \\
190.210^{\text {ee }} \\
192.977^{\mathrm{dd}} \\
196^{\mathrm{r}}\end{array}$ & $\begin{array}{l}4.892^{\mathrm{h}} \\
4.791^{\mathrm{dd}}, \\
4.289^{\mathrm{ee}} \\
4.32^{\mathrm{ff}} \\
4.2^{\mathrm{r}}\end{array}$ \\
\hline Wurtzite (B4) This work & 3.188 & 5.188 & 1.62 & 189.594 & 4.518 \\
\hline Experiment & $3.189^{\mathrm{gg}}$ & $5.185^{\mathrm{gg}}$ & $1.625^{\mathrm{gg}}$ & & \\
\hline
\end{tabular}




\begin{tabular}{|l|l|l|l|l|l|}
\hline & $3.9^{\mathrm{a} 6}$ & $5.18^{\mathrm{a} 6}$ & & & \\
\hline Theory & $3.22^{\mathrm{cc}}$ & $5.24^{\mathrm{cc}}$ & $1.62^{\mathrm{cc}}$ & $175.794^{\mathrm{ee}}$ & $4.37^{\mathrm{p}}$ \\
& $3.59^{\mathrm{ii}}$ & $5.81^{\mathrm{ii}}$ & $1.616^{\mathrm{ee}}$ & $176.54^{\mathrm{p}}$ & $4.3^{\mathrm{r}}, 3.950^{\mathrm{ee}}$ \\
& $3.189^{\mathrm{ee}}$ & $5.153^{\mathrm{ee}}$ & $1.616^{\mathrm{p}}$ & $196^{\mathrm{r}}$ & \\
& $3.221^{\mathrm{p}}$ & $5.205^{\mathrm{p}}$ & $1.632^{\mathrm{r}}$ & & \\
& $3.180^{\mathrm{r}}$ & $5.189^{\mathrm{r}}$ & & & \\
\hline
\end{tabular}

${ }^{a}$ Ref. [71].

${ }^{b}$ Ref. [72].

${ }^{\mathrm{c}}$ Ref. [73].

${ }^{\mathrm{d}}$ Ref. [74].

${ }^{\mathrm{e}}$ Ref. [75].

${ }^{\mathrm{f}}$ Ref. [35].

${ }^{\mathrm{g}}$ Ref. [57].

${ }^{\mathrm{h}}$ Ref. [76].

${ }^{\mathrm{i}}$ Ref. [77].

${ }^{j}$ Ref. [33].

${ }^{\mathrm{k}}$ Ref. [78].

${ }^{1}$ Ref. [79].

${ }^{\mathrm{m}}$ Ref. [80].

${ }^{\mathrm{n}}$ Ref. [34].

${ }^{\circ}$ Ref. [81].

${ }^{\mathrm{p}}$ Ref. [67].

${ }^{\mathrm{q}}$ Ref. [62].

${ }^{\mathrm{r}}$ Ref. [63].

${ }^{\mathrm{s}}$ Ref. [82].

${ }^{t}$ Ref. [83].

uef. [84].

${ }^{v}$ Ref. [60].

${ }^{w}$ Ref. [85].

${ }^{x}$ Ref. [86].

${ }^{\mathrm{y}}$ Ref. [87].

${ }^{\mathrm{z}}$ Ref. [88].

${ }^{\text {aa }}$ Ref. [89].

${ }^{\mathrm{bb}}$ Ref. [90].

${ }^{c c}$ Ref. [91].

${ }^{d d}$ Ref. [92].

${ }^{\mathrm{ee}}$ Ref. [66].

${ }^{\text {ff }}$ Ref. [93].

${ }^{\text {gg }}$ Ref. [94].

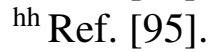

${ }^{i i}$ Ref. [96]. 
Table 3: Calculated band gap energy $\mathrm{E}_{\mathrm{g}}(\mathrm{eV})$ using $\mathrm{mBJ}$ approximation for $\mathrm{GaN}_{\mathrm{x}} \mathrm{As}_{1-\mathrm{x}}$ alloys with stable phase compared with experimental results and other theoretical works

\begin{tabular}{|l|l|l|l|l|l|l|}
\hline $\mathbf{G a N}_{\mathbf{x}} \mathbf{A s}_{1-\mathbf{x}}$ & Phase & This work & Expt. & \multicolumn{3}{|c|}{ Other work } \\
\hline $\mathrm{GaAs}$ & $\mathrm{B} 3$ & 1.559 & $1.42^{\mathrm{a}}$ & $\begin{array}{l}1.559^{\mathrm{b}}, 1.65^{\mathrm{c}, \mathrm{d}} \\
1.560^{\mathrm{e}}, 1.390^{\mathrm{f}, \mathrm{g}}\end{array}$ & $1.562^{\mathrm{h}}$ & $0.624^{\mathrm{i}}$ \\
\hline $\mathrm{GaN}_{0.25} \mathrm{As}_{0.75}$ & $\mathrm{~B} 3$ & 0.725 & & & $1.350^{\mathrm{h}}$ & $0.38^{\mathrm{i}}$ \\
\hline $\mathrm{GaN}_{0.5} \mathrm{As}_{0.5}$ & $\mathrm{~B} 3$ & 1.290 & & $0.841^{\mathrm{j}}$ & $1.461^{\mathrm{h}}$ & $0.655^{\mathrm{i}}$ \\
\hline $\mathrm{GaN}_{0.75} \mathrm{As}_{0.25}$ & $\mathrm{~B} 3$ & 2.004 & & & $1.991^{\mathrm{h}}$ & $1.182^{\mathrm{i}}$ \\
\hline $\mathrm{GaN}$ & $\mathrm{B} 4$ & 3.190 & $\begin{array}{l}3.45^{\mathrm{a}}, 3.42^{\mathrm{k}}, 3.5^{1}, \\
3.44^{\mathrm{m}}, 3.556^{\mathrm{n}}\end{array}$ & $3.33^{\mathrm{o}}, 3.09^{\mathrm{p}}, 3.32^{\mathrm{q}}$ & & \\
\hline
\end{tabular}

${ }^{a}$ Ref. [17].

${ }^{\mathrm{b}}$ Ref. [57].

${ }^{\mathrm{c}}$ Ref. [103].

${ }^{\mathrm{d}}$ Ref. [104].

${ }^{\mathrm{e}}$ Ref. [105].

${ }^{\mathrm{f}}$ Ref. [77].

${ }^{\mathrm{g}}$ Ref. [106].

${ }^{\mathrm{h}}$ Ref. [35].

${ }^{\mathrm{i}}$ Ref. [33].

${ }^{\mathrm{j}}$ Ref. [34].

${ }^{\mathrm{k}}$ Ref. [107].

${ }^{1}$ Ref. [74].

${ }^{\mathrm{m}}$ Ref. [108].

${ }^{\mathrm{n}}$ Ref. [109].

${ }^{\circ}$ Ref. [91].

${ }^{\mathrm{p}}$ Ref. [110].

${ }^{\mathrm{q}}$ Ref. [111]. 
Table 4: Calculated static values of static dielectric constant $\varepsilon_{1}(0)$, static refractive indices $\mathrm{n}(0)$ and reflectivity $\mathrm{R}(0)$ using $\mathrm{mBJ}$ schemes with other theoretical models.

\begin{tabular}{|c|c|c|c|c|c|c|c|}
\hline \multirow[b]{2}{*}{$\mathrm{GaN}_{\mathrm{x}} \mathrm{As}_{1-\mathrm{x}}$} & \multicolumn{2}{|c|}{ Present work } & \multirow[t]{2}{*}{ Herve. } & \multirow[t]{2}{*}{ Ravindra. } & \multirow[t]{2}{*}{ Moss } & \multirow[t]{2}{*}{ Expt. } & \multirow[t]{2}{*}{ Other work } \\
\hline & Parameters & $\mathrm{mBJ}$ & & & & & \\
\hline \multirow[t]{3}{*}{$x=0$} & $\varepsilon_{1}(0)$ & 9.572 & 8.521 & 9.718 & 8.323 & $10.90^{\mathrm{a}}$ & $\begin{array}{l}9.699^{\mathrm{b}}, 9.58^{\mathrm{c}}, 10.327^{\mathrm{d}}, \\
11.48^{\mathrm{e}}, 13.40^{\mathrm{f}}, 14.13^{\mathrm{g}}\end{array}$ \\
\hline & $\mathrm{n}(0)$ & 3.094 & 2.919 & 3.117 & 2.884 & $3.30^{\mathrm{a}}$ & $\begin{array}{l}3.114^{\mathrm{b}}, 3.213^{\mathrm{d}}, 3.76^{\mathrm{g}}, \\
3.81^{\mathrm{f}}\end{array}$ \\
\hline & $\mathrm{R}(0)$ & 0.261 & & & & & $0.276^{\mathrm{d}}$ \\
\hline \multirow[t]{3}{*}{$\mathrm{x}=0.25$} & $\varepsilon_{1}(0)$ & 9.179 & 11.87 & 13.209 & 12.205 & & $11^{\mathrm{h}}$ \\
\hline & $\mathrm{n}(0)$ & 3.029 & 3.445 & 3.634 & 3.493 & & \\
\hline & $\mathrm{R}(0)$ & 0.253 & & & & & $0.3^{\mathrm{h}}$ \\
\hline \multirow[t]{3}{*}{$x=0.5$} & $\varepsilon_{1}(0)$ & 7.687 & 9.408 & 10.785 & 9.149 & & $9^{\mathrm{h}}, 8.07^{\mathrm{e}}$ \\
\hline & $\mathrm{n}(0)$ & 2.772 & 3.067 & 3.284 & 3.024 & & \\
\hline & $\mathrm{R}(0)$ & 0.220 & & & & & $0.25^{\mathrm{h}}$ \\
\hline \multirow[t]{3}{*}{$\mathrm{x}=0.75$} & $\varepsilon_{1}(0)$ & 6.051 & 7.333 & 8.074 & 7.341 & & $7^{\mathrm{h}}$ \\
\hline & $\mathrm{n}(0)$ & 2.459 & 2.708 & 2.841 & 2.709 & & \\
\hline & $\mathrm{R}(0)$ & 0.178 & & & & & $0.2^{\mathrm{h}}$ \\
\hline \multirow[t]{3}{*}{$\mathrm{x}=1$} & $\varepsilon_{1}(0)$ & 4.275 & 5.258 & 4.436 & 5.818 & & $4.120^{\mathrm{i}}$ \\
\hline & $\mathrm{n}(0)$ & 2.067 & 2.293 & 2.106 & 2.412 & & $2.03^{\mathrm{i}}$ \\
\hline & $\mathrm{R}(0)$ & 0.121 & & & & & \\
\hline
\end{tabular}

${ }^{a}$ Ref. [116].

${ }^{b}$ Ref. [106].

${ }^{\mathrm{c}}$ Ref. [76].

${ }^{\mathrm{d}}$ Ref. [57].

${ }^{\mathrm{e}}$ Ref. [36].

${ }^{\mathrm{f}}$ Ref. [117].

${ }^{\mathrm{g}}$ Ref. [77].

${ }^{\mathrm{h}}$ Ref. [40].

${ }^{\mathrm{i}} \operatorname{Ref}$ [91]. 

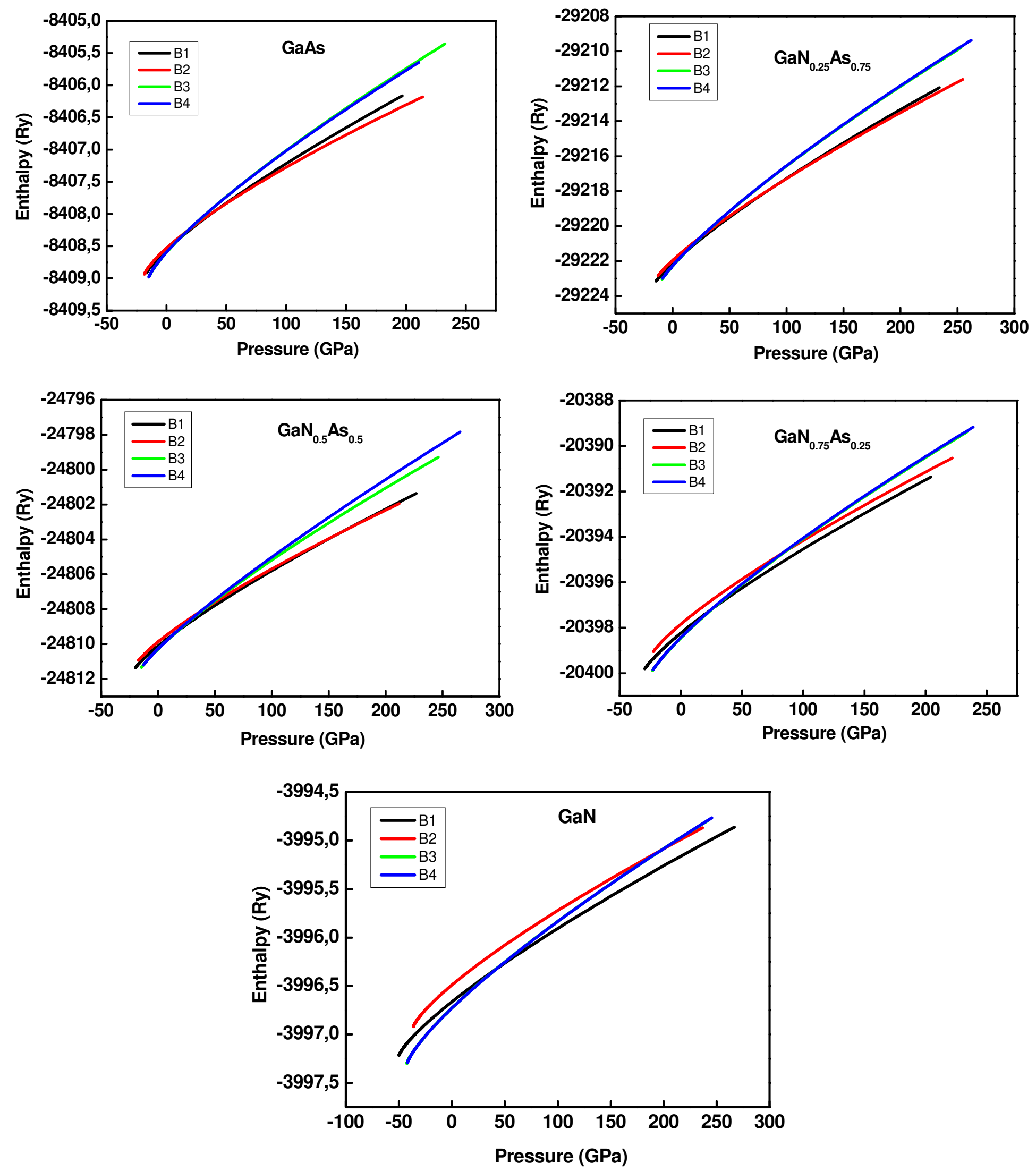

Fig. 2. Calculated enthalpy as a function of pressure for $\mathrm{GaN}_{\mathrm{x}} \mathrm{As}_{1-\mathrm{x}}$ using WC-GGA approximation. 


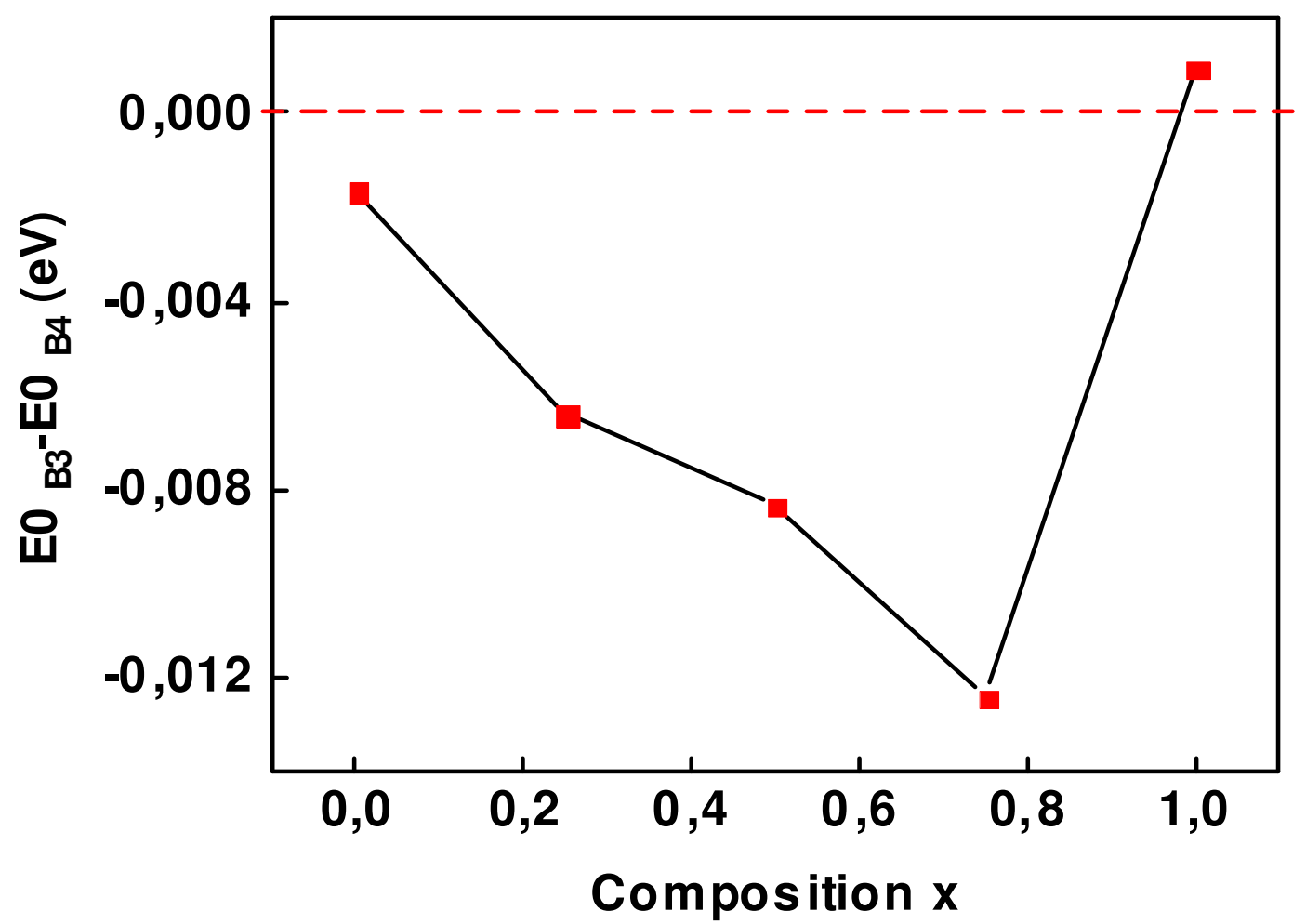

Fig. 3. Variation in the $\Delta \mathrm{E}_{0}$ as a function of the composition for ternary alloys $\mathrm{GaN}_{\mathrm{x}} \mathrm{As} \mathrm{s}_{1-\mathrm{x}}$. 


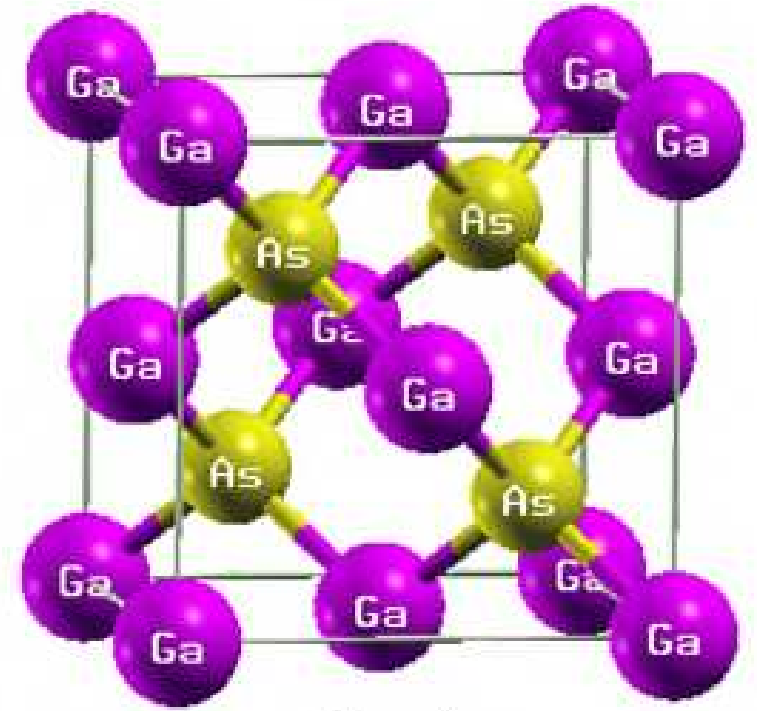

GaAs

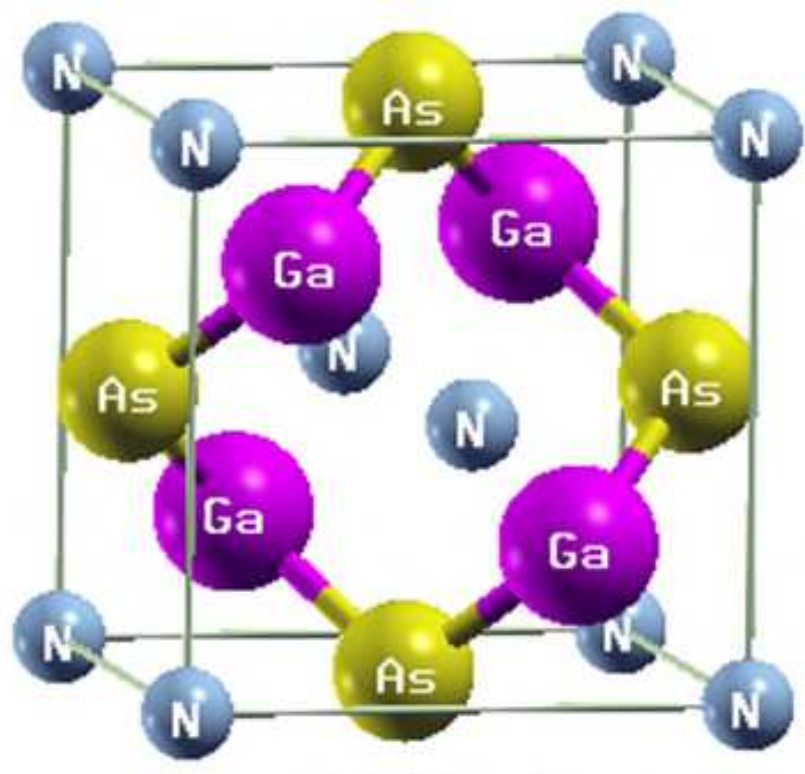

$\mathrm{GaN}_{0.5} \mathrm{As}_{0.5}$

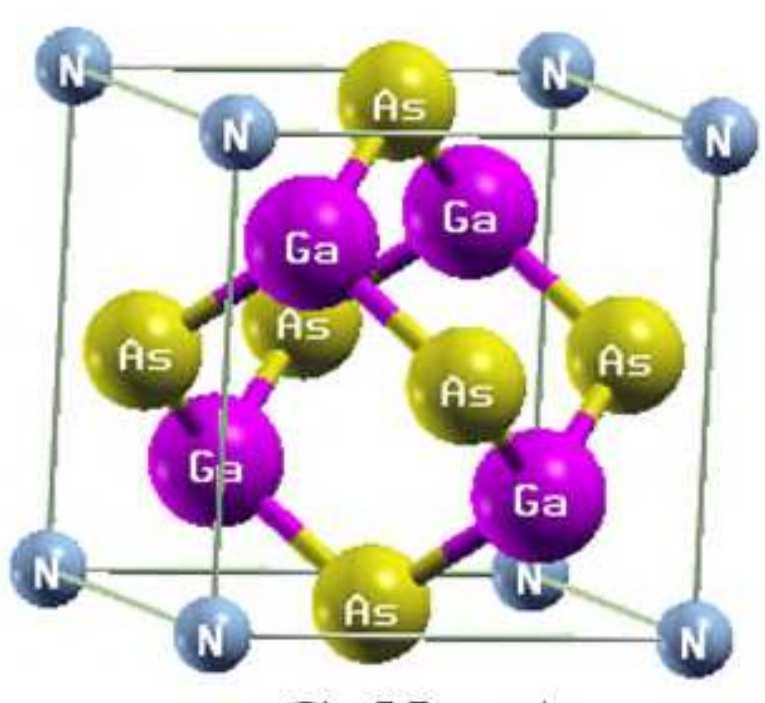

$\mathrm{GaN}_{0.25} \mathrm{As}_{0.75}$
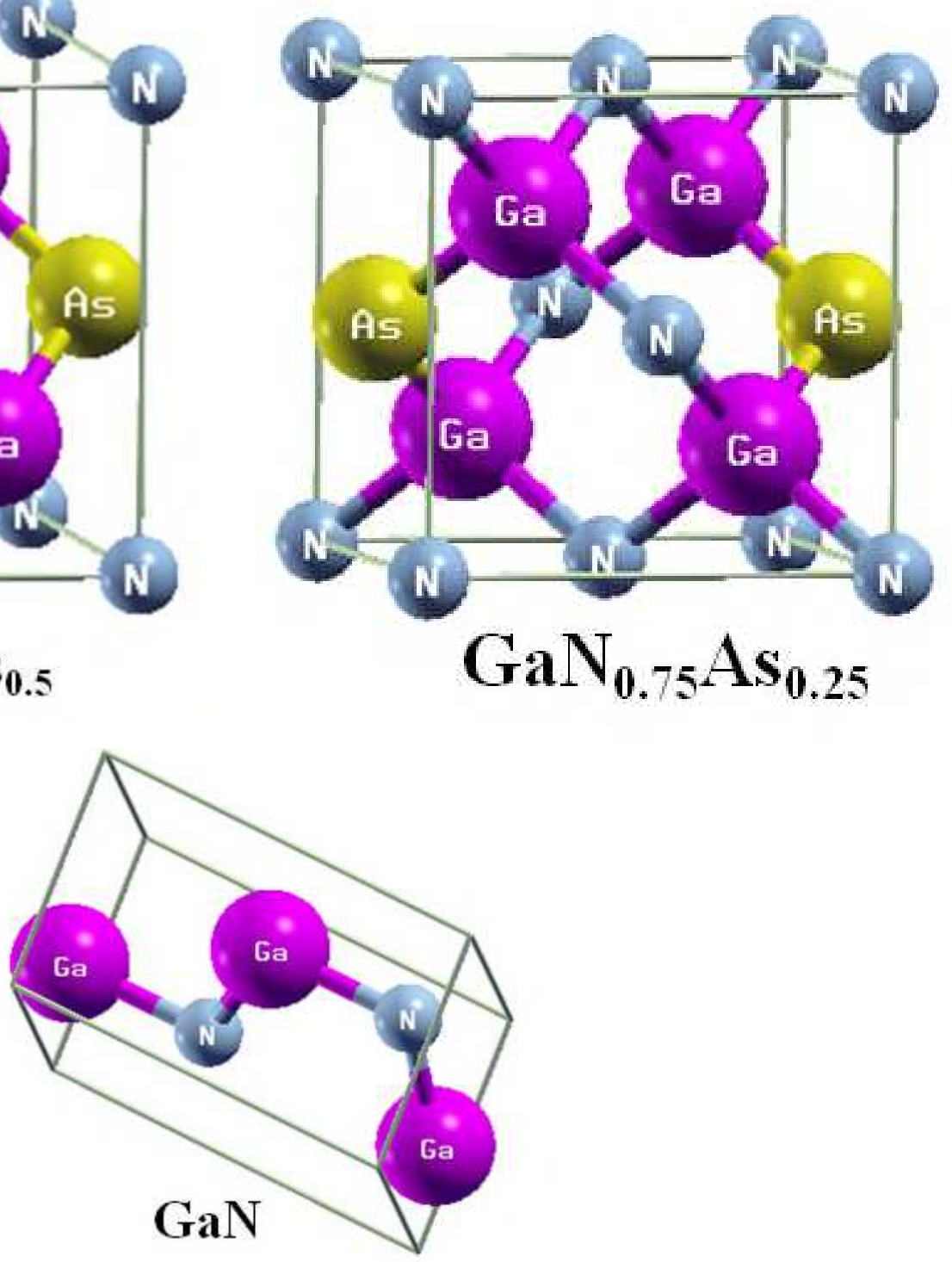

Fig. 4. Crystal structure of $\mathrm{GaN}_{\mathrm{x}} \mathrm{As}_{1-\mathrm{x}}$. 

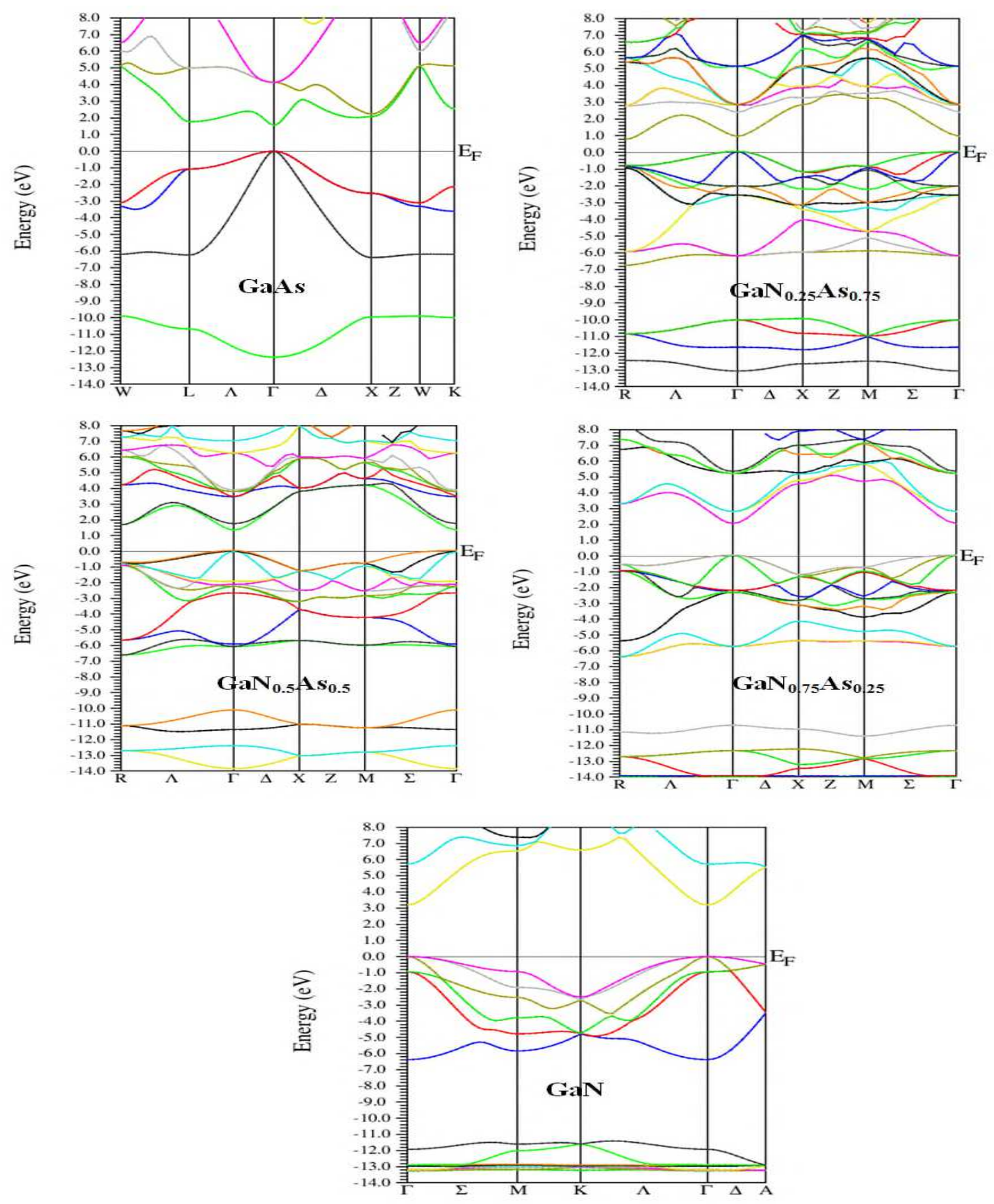

Fig. 5. Calculated band structures of $\mathrm{GaN}_{\mathrm{x}} \mathrm{As}_{1-\mathrm{x}}$ using $\mathrm{mBJ}$ approximation. 


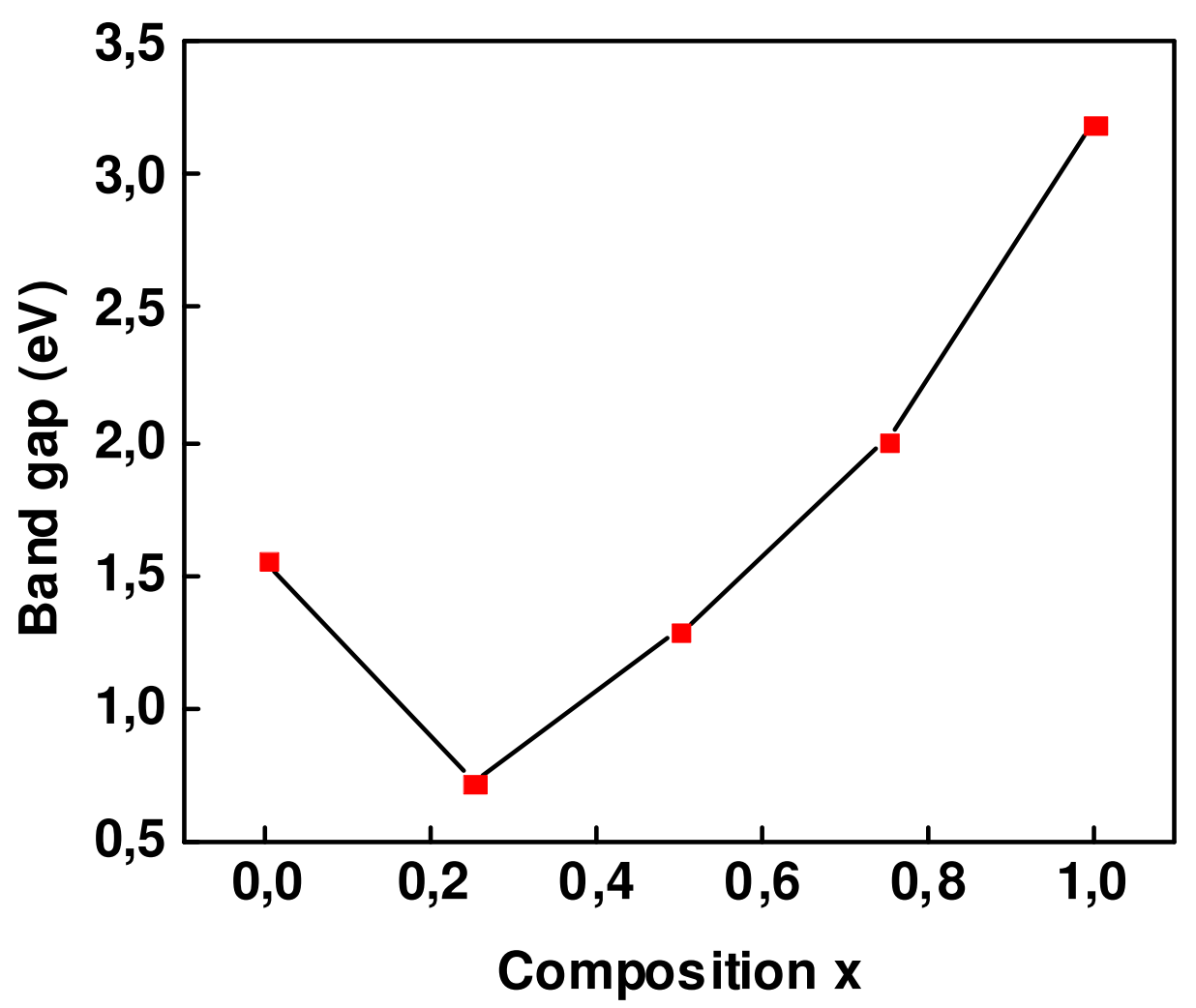

Fig.6. Calculated band gap energy using the $\mathrm{mBJ}$ approximation of $\mathrm{GaN}_{\mathrm{x}} \mathrm{As}_{1-\mathrm{x}}$ ternary alloys. 

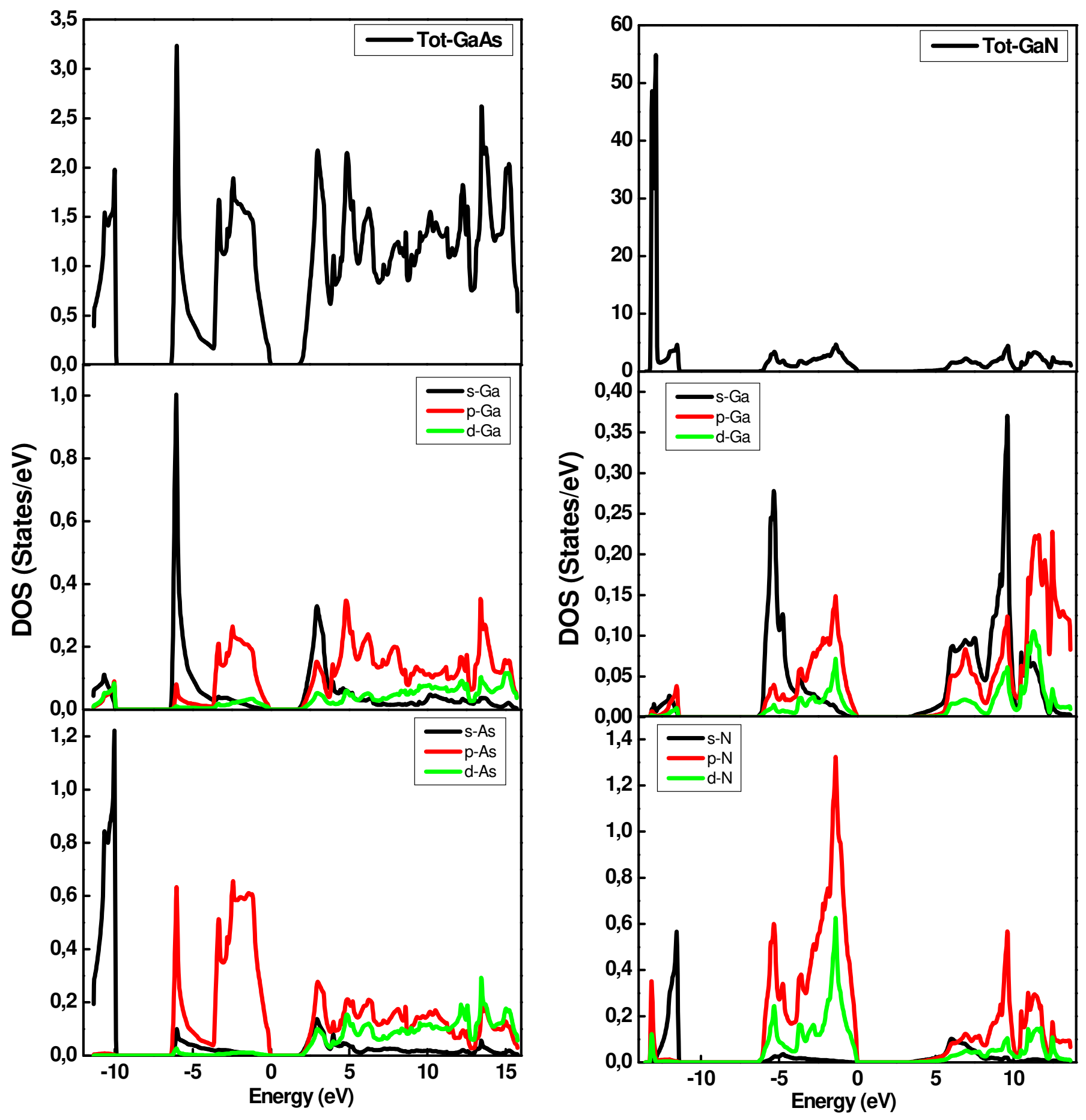

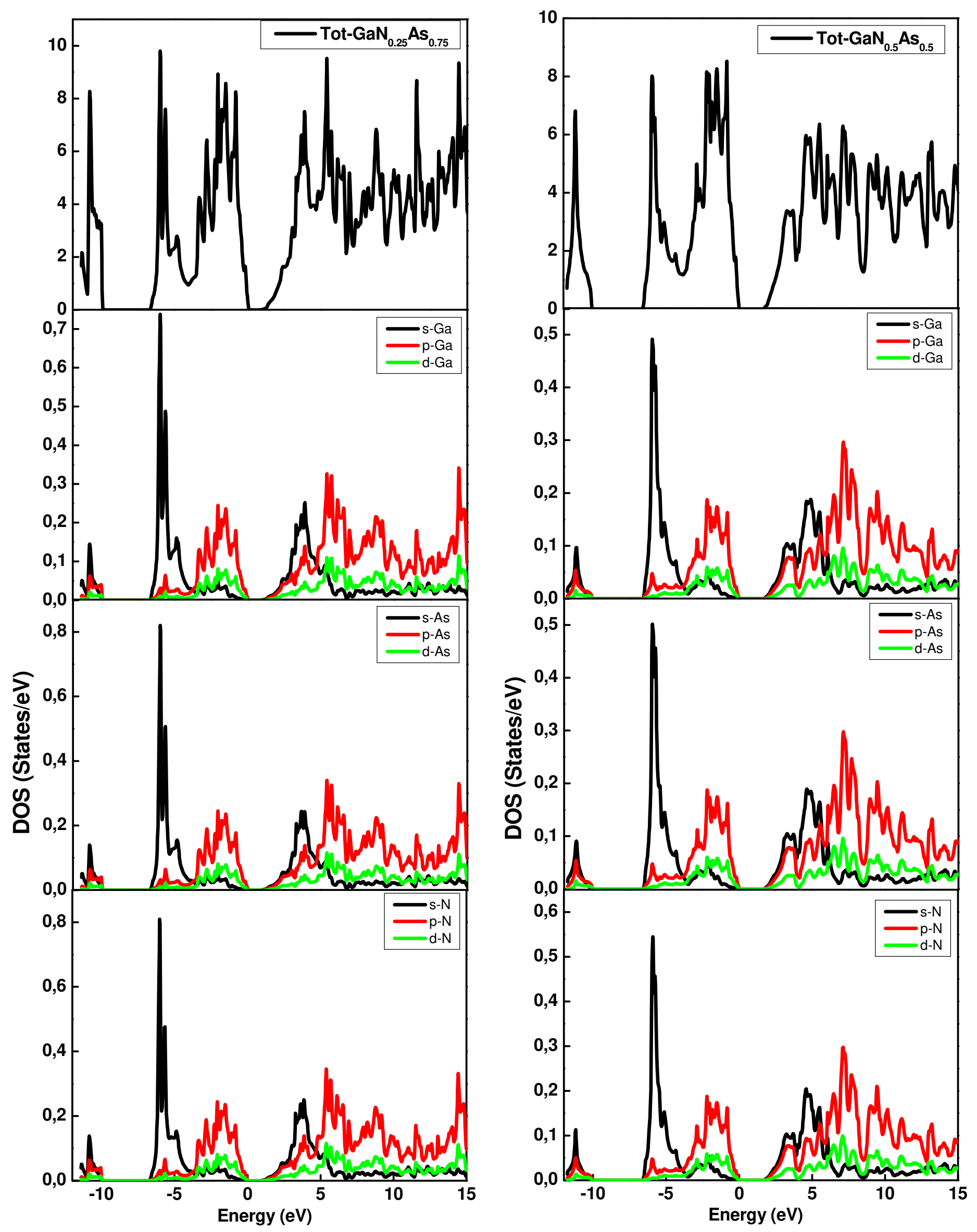


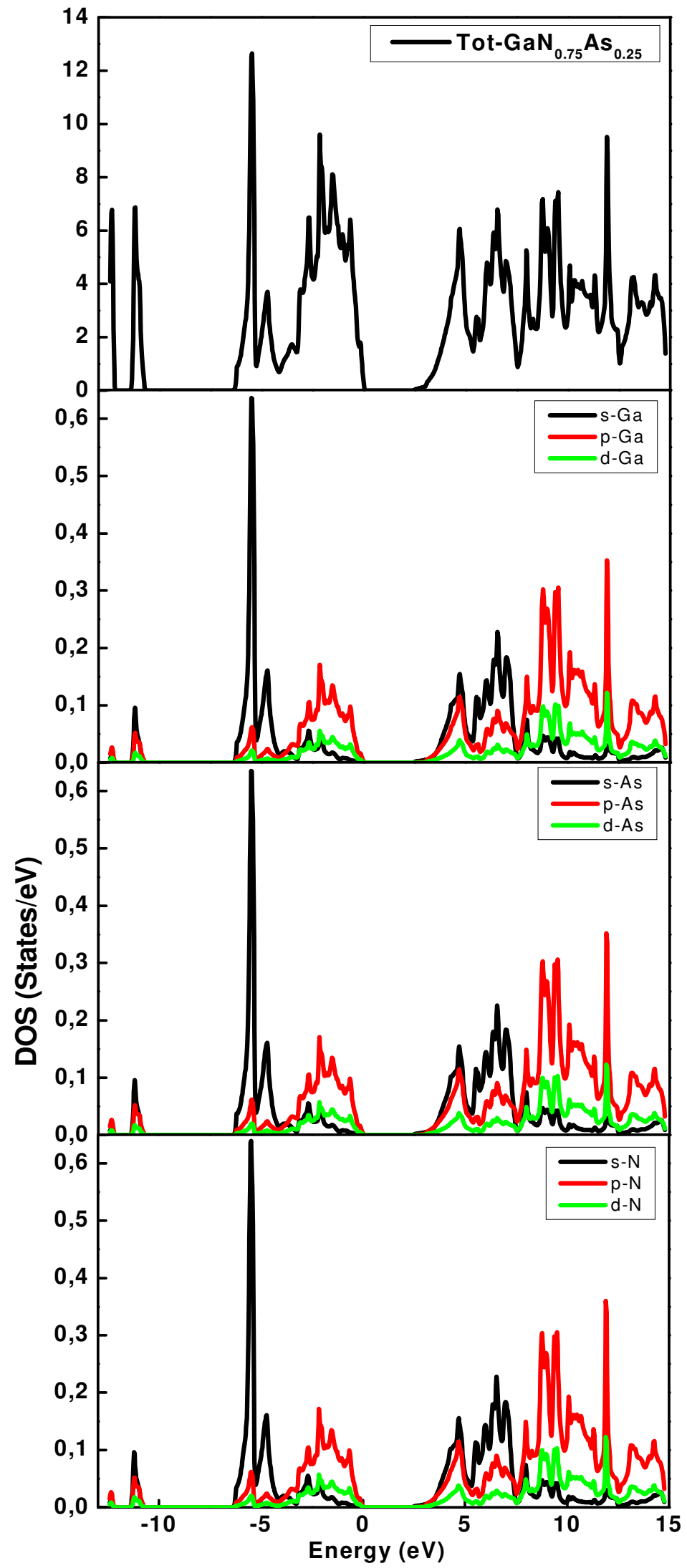

Fig.7. Calculated total and partial density of states of $\mathrm{GaN}_{\mathrm{x}} \mathrm{As}_{1-\mathrm{x}}$ ternary alloys using the $\mathrm{mBJ}$ approximation. 

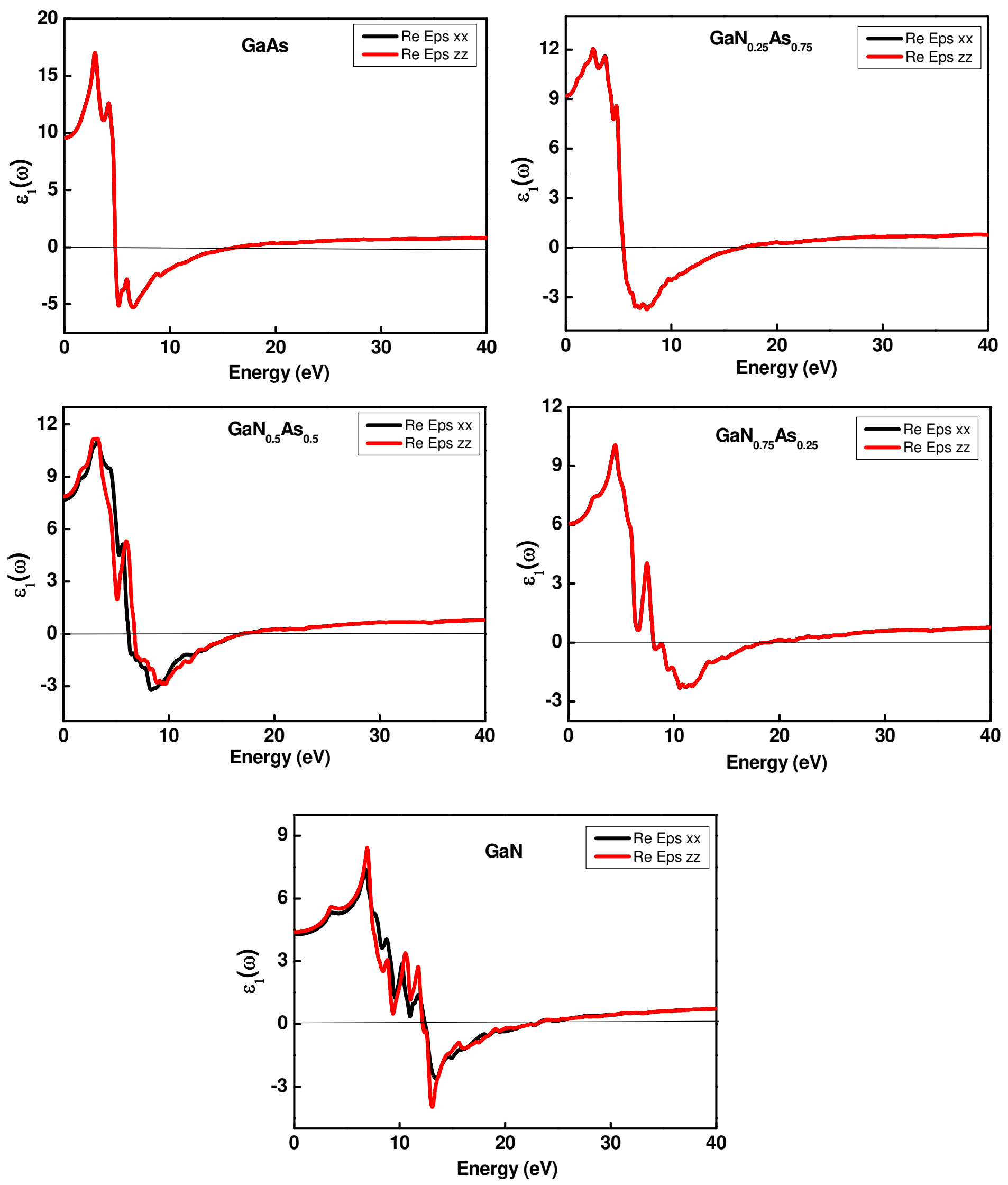

Fig. 8. Variation of real part of the dielectric function versus energy of $\mathrm{GaN}_{\mathrm{x}} \mathrm{As}_{1-\mathrm{x}}$ ternary alloys using $\mathrm{mBJ}$ approximation . 

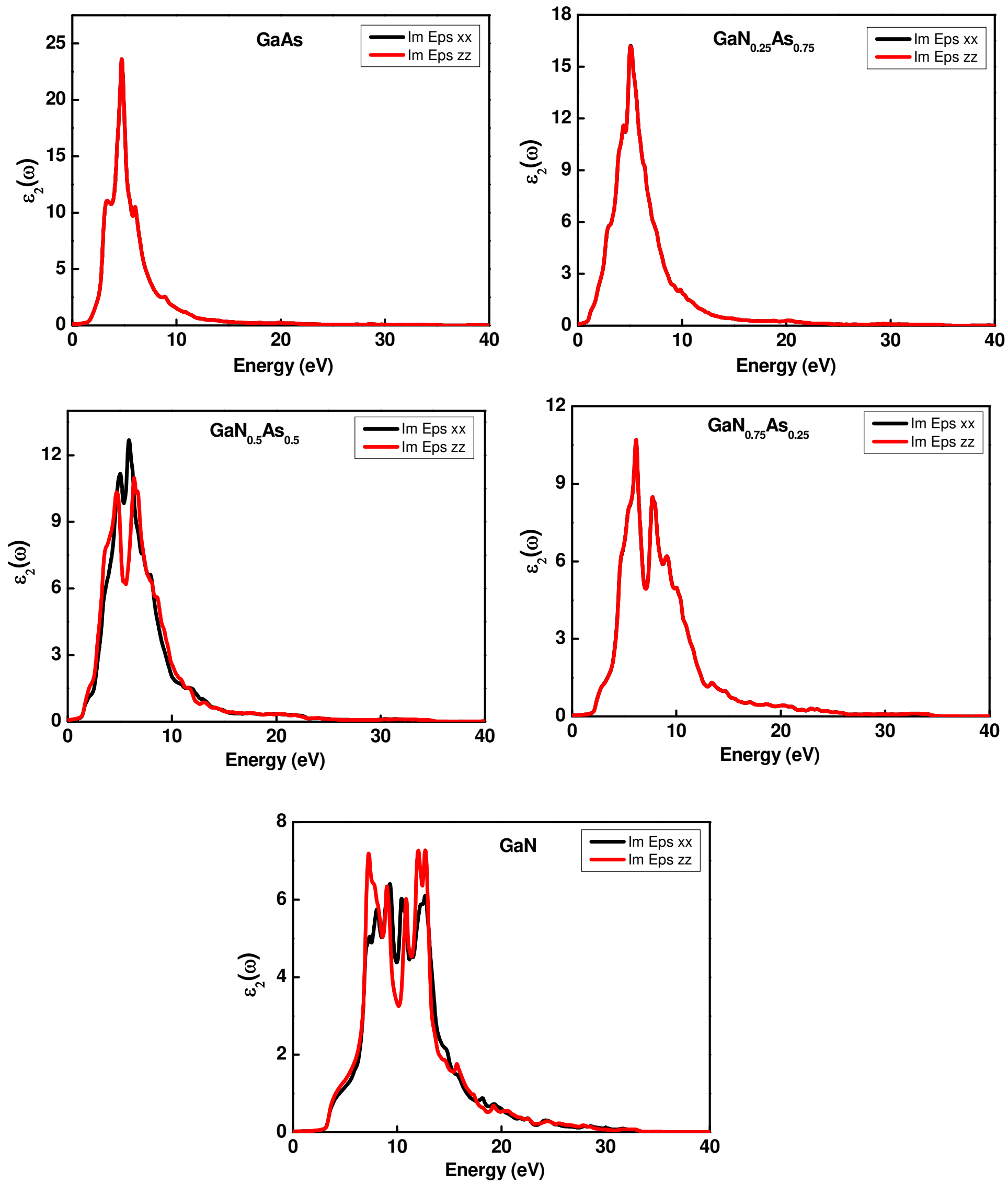

Fig. 9. Variation of imaginary part of the dielectric function versus energy of $\mathrm{GaN}_{\mathrm{x}} \mathrm{As} \mathrm{s}_{1-\mathrm{x}}$ ternary alloys using $\mathrm{mBJ}$ approximation. 

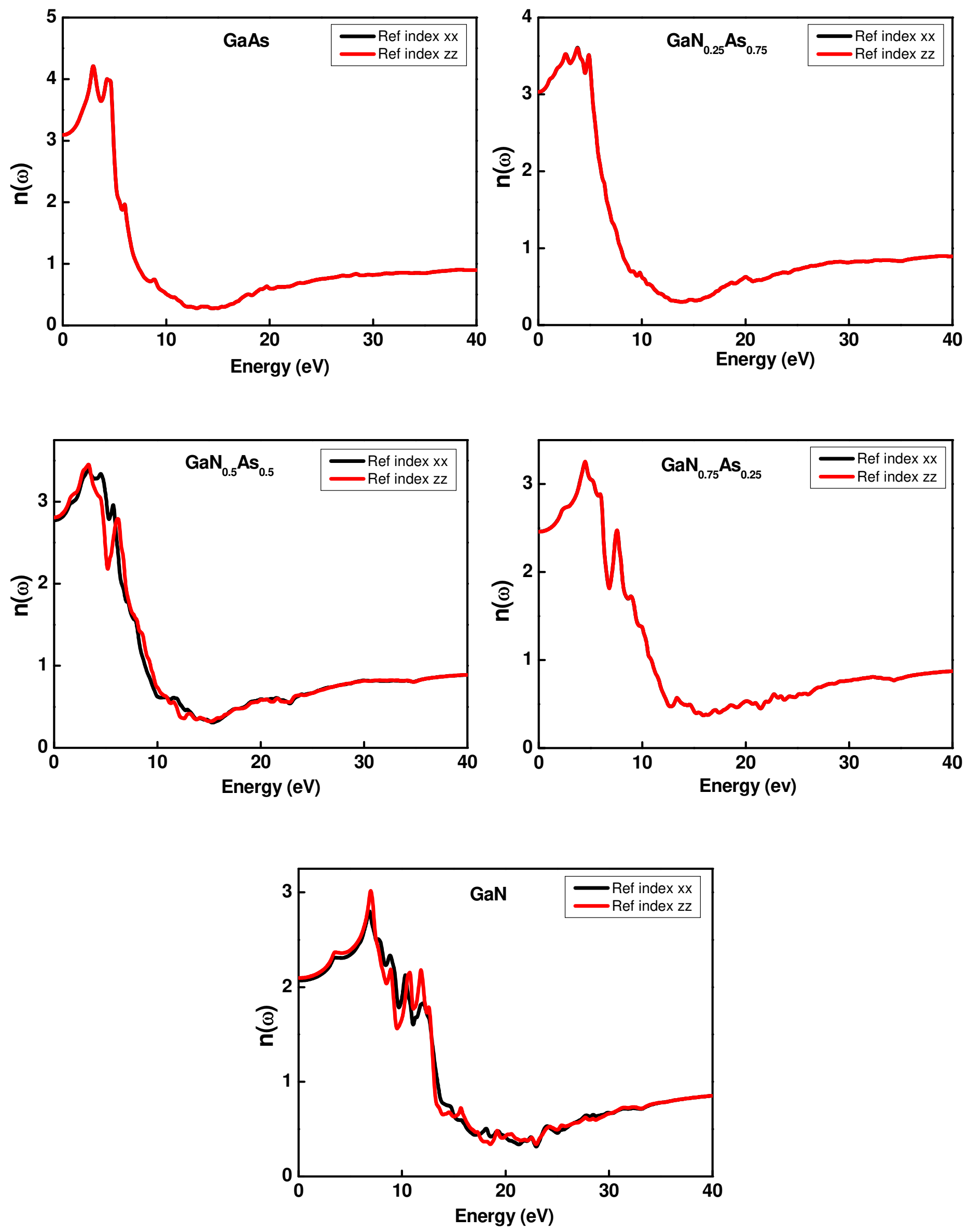

Fig. 10. Variation of refractive index versus energy of $\mathrm{GaN}_{\mathrm{x}} \mathrm{As} \mathrm{s}_{1-\mathrm{x}}$ ternary alloys using mBJ approximation. 

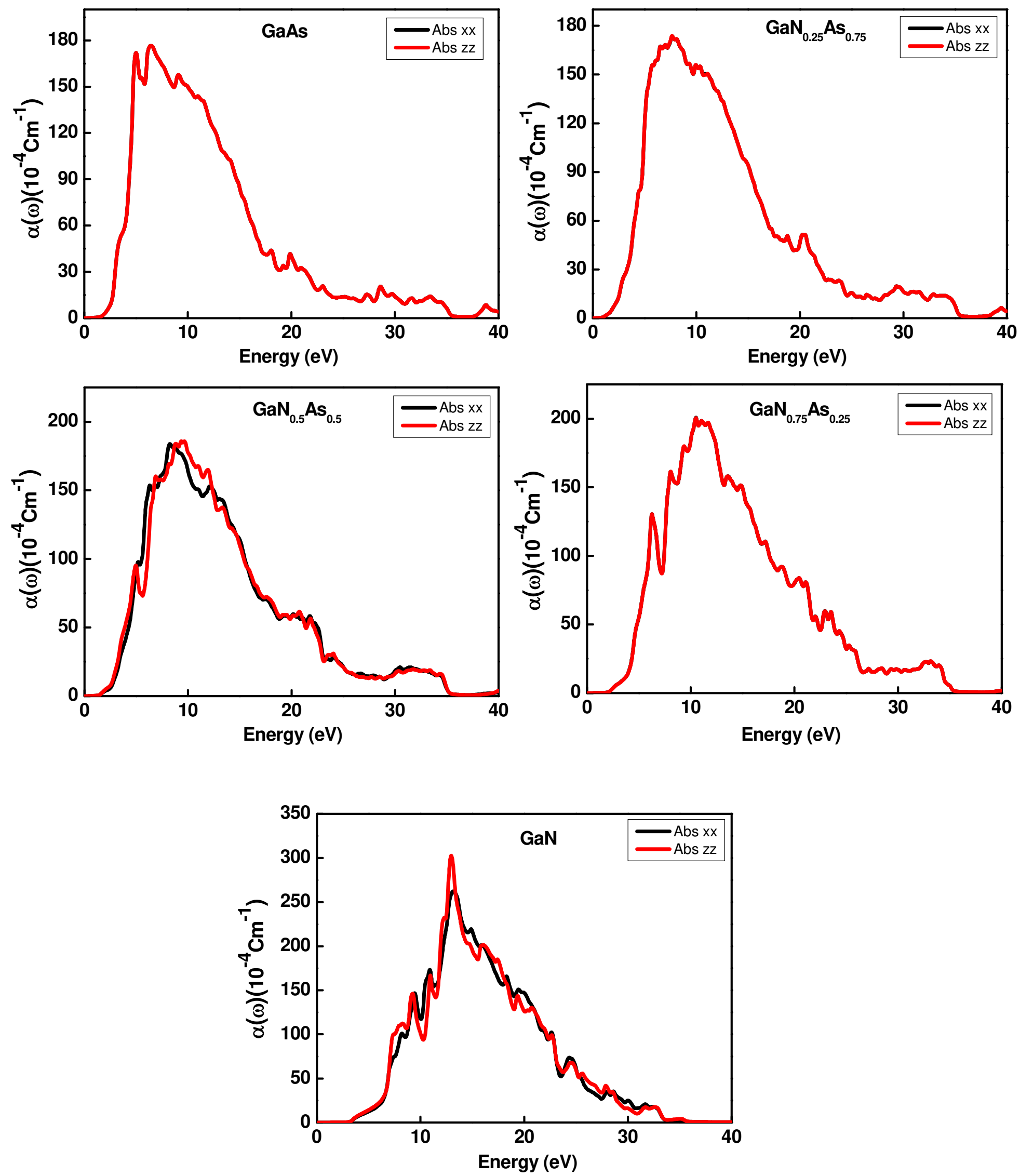

Fig. 11. Variation of absorption coefficient versus energy of $\mathrm{GaN}_{\mathrm{x}} \mathrm{As} \mathrm{s}_{1-\mathrm{x}}$ ternary alloys using mBJ approximation. 

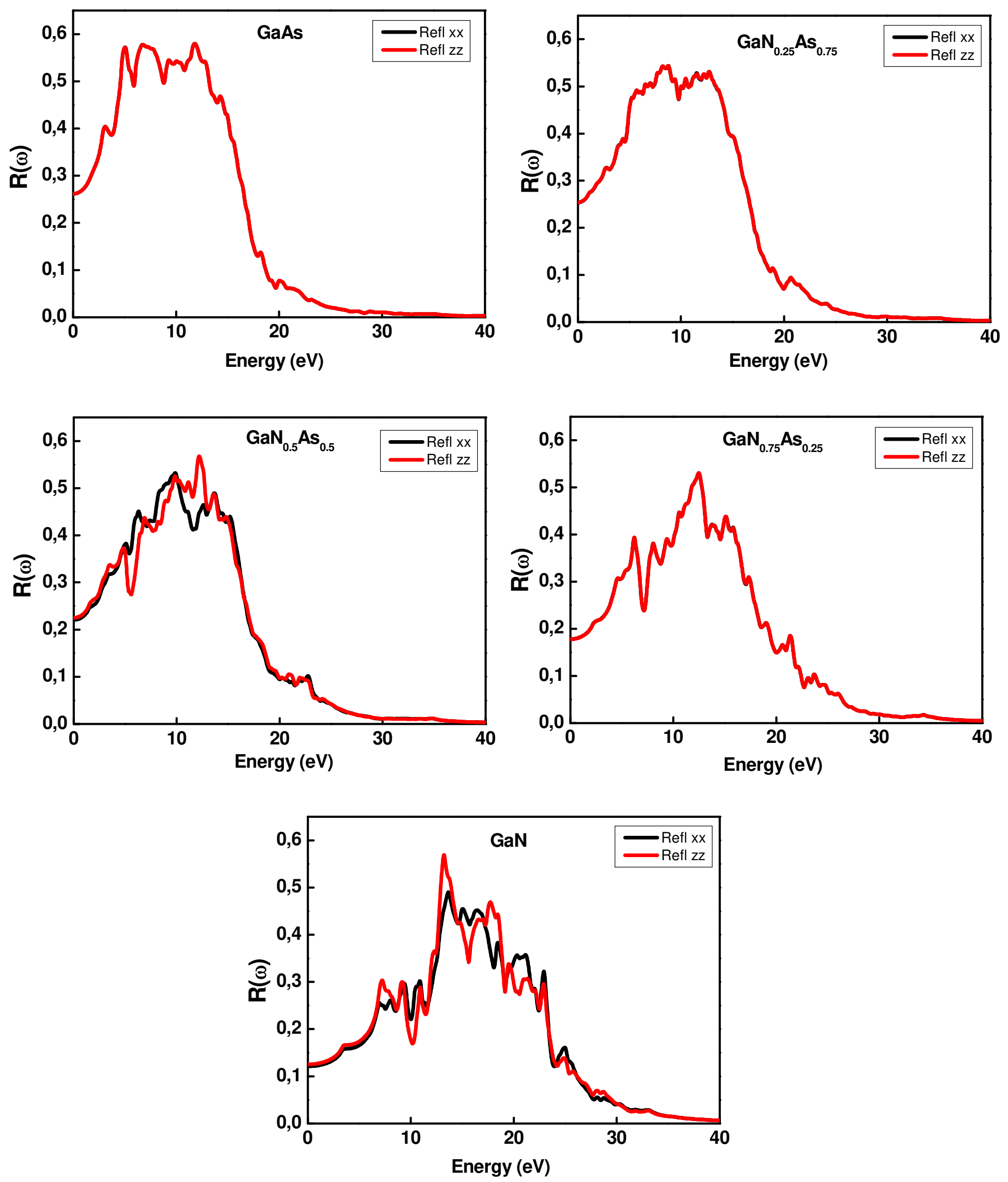

Fig. 12. Variation of refractivity versus energy of $\mathrm{GaN}_{\mathrm{x}} \mathrm{As}_{1-\mathrm{x}}$ ternary alloys using mBJ approximation. 

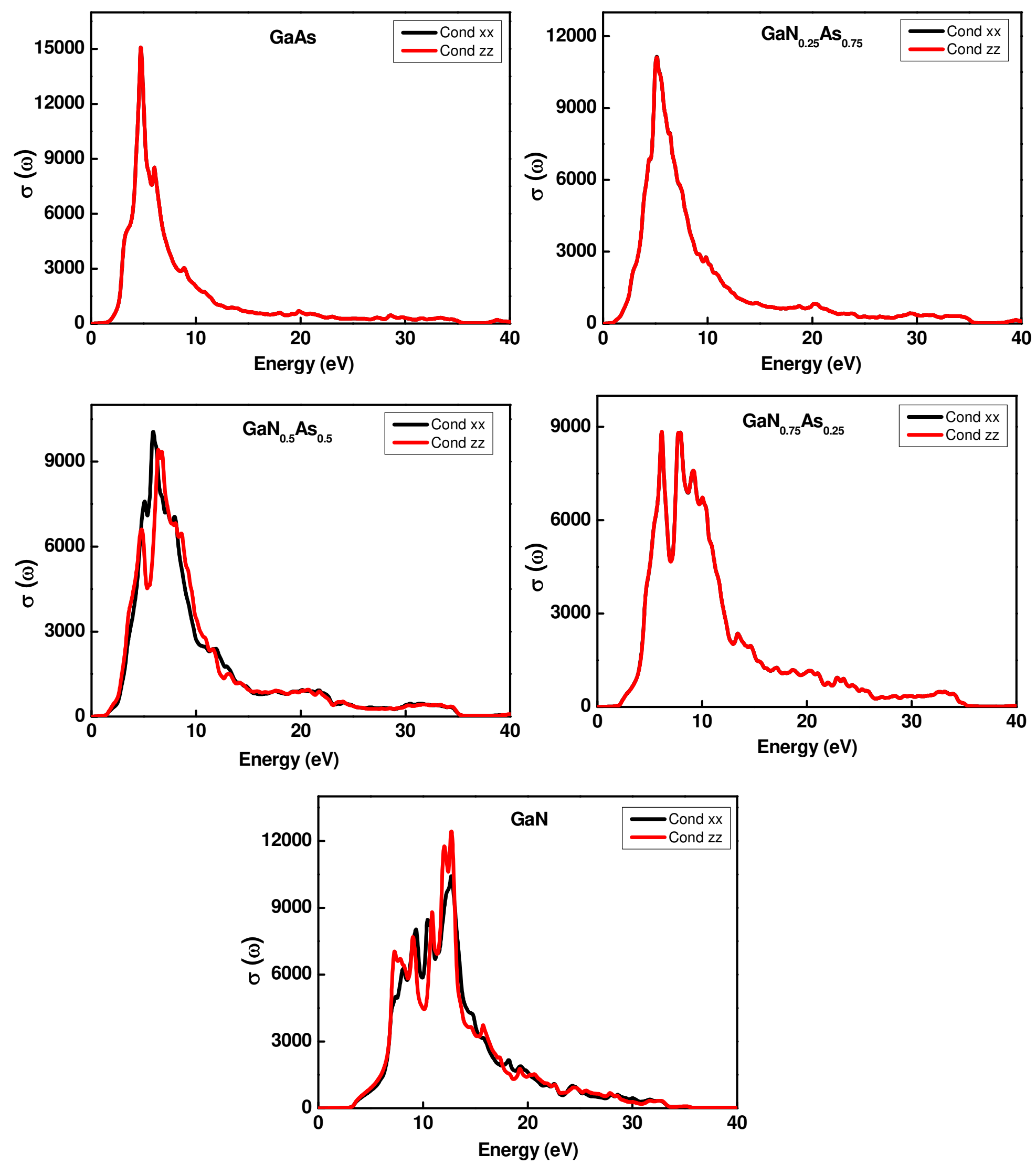

Fig. 13. Variation of conductivity versus energy of $\mathrm{GaN}_{\mathrm{x}} \mathrm{As} \mathrm{s}_{1-\mathrm{x}}$ ternary alloys using mBJ approximation. 

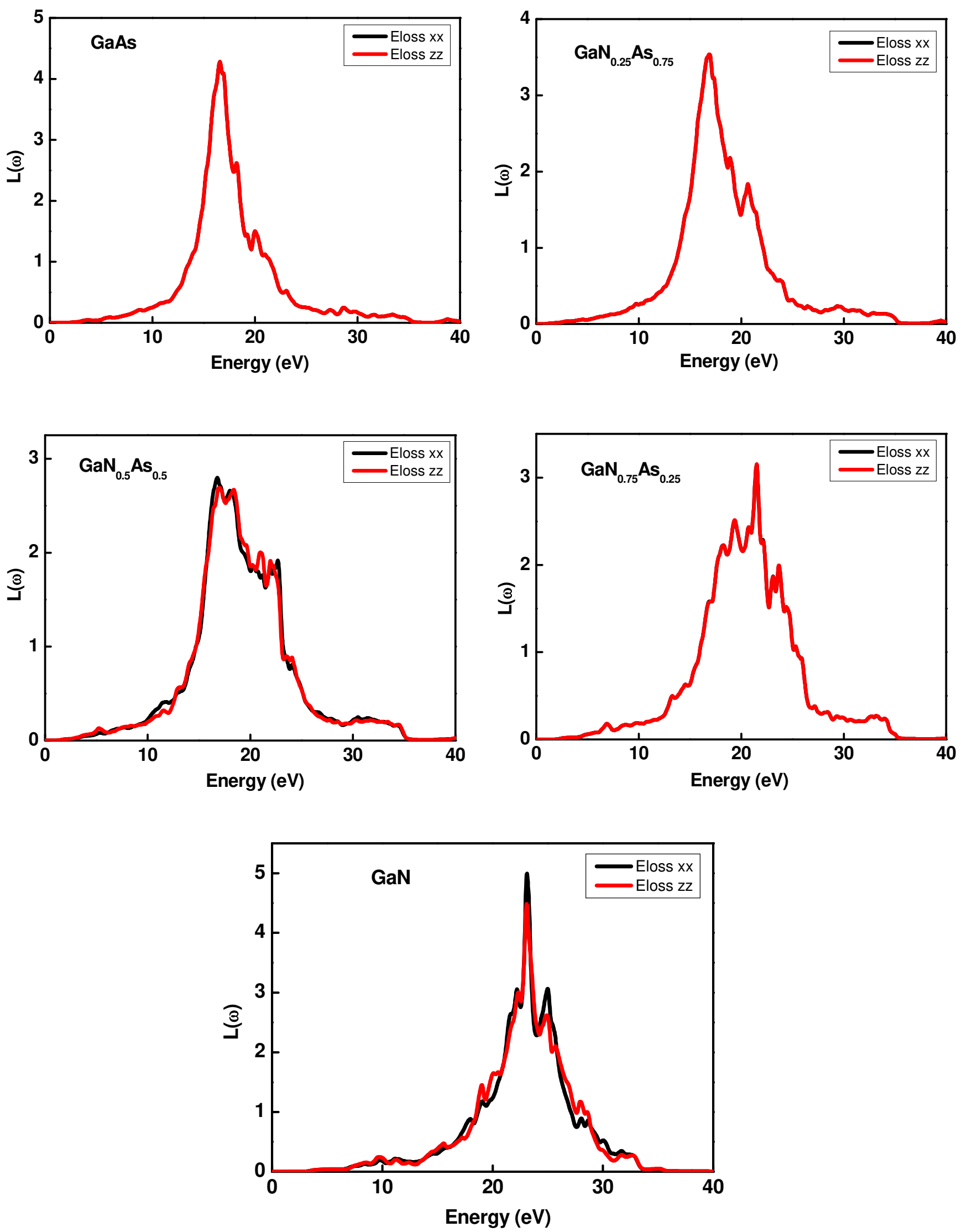

Fig. 14. Variation of energy loss versus energy of $\mathrm{GaN}_{\mathrm{x}} \mathrm{As}_{1-\mathrm{x}}$ ternary alloys using mBJ approximation. 


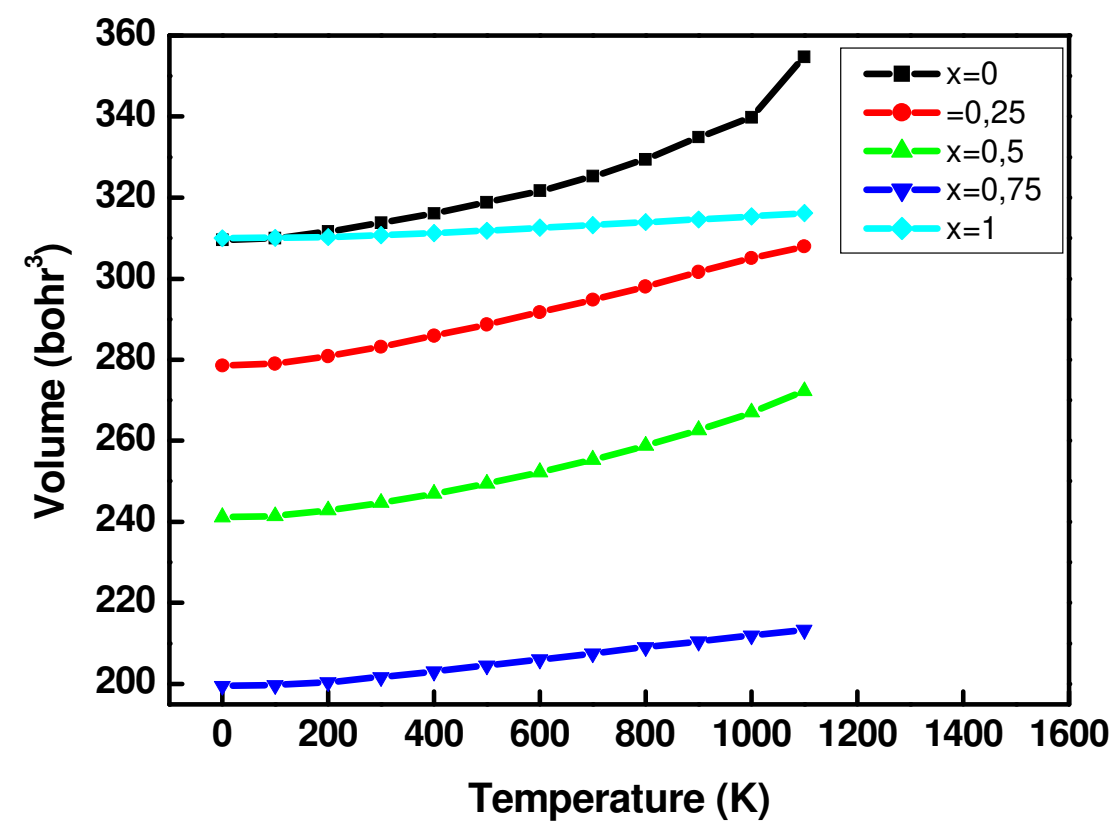

Fig. 15. Variation of the volume with temperature at $\mathrm{P}=0 \mathrm{GPa}$ of the $\mathrm{GaN}_{\mathrm{x}} \mathrm{As} \mathrm{s}_{1-\mathrm{x}}$ ternary alloys.

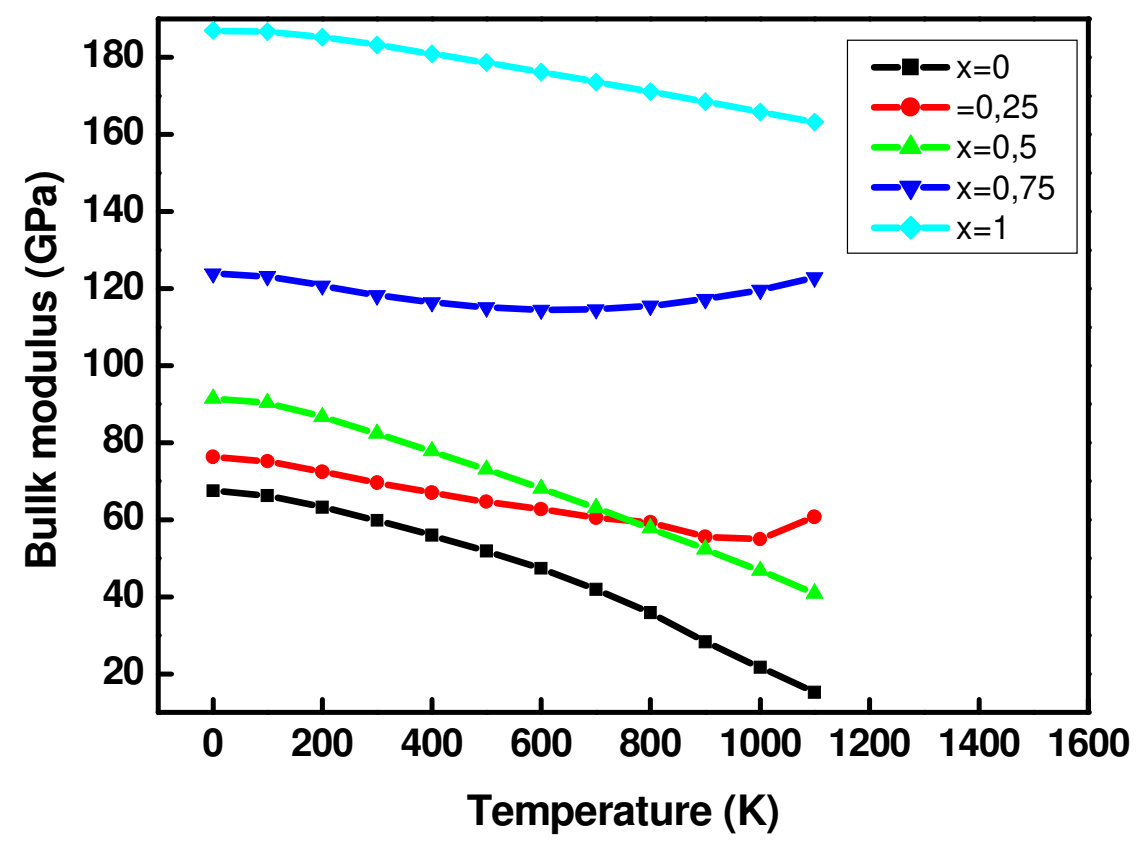

Fig. 16. Variation of the bullk modulus with temperature at $\mathrm{P}=0 \mathrm{GPa}$ of the $\mathrm{GaN}_{\mathrm{x}} \mathrm{As} \mathrm{s}_{1-\mathrm{x}}$ ternary alloys. 


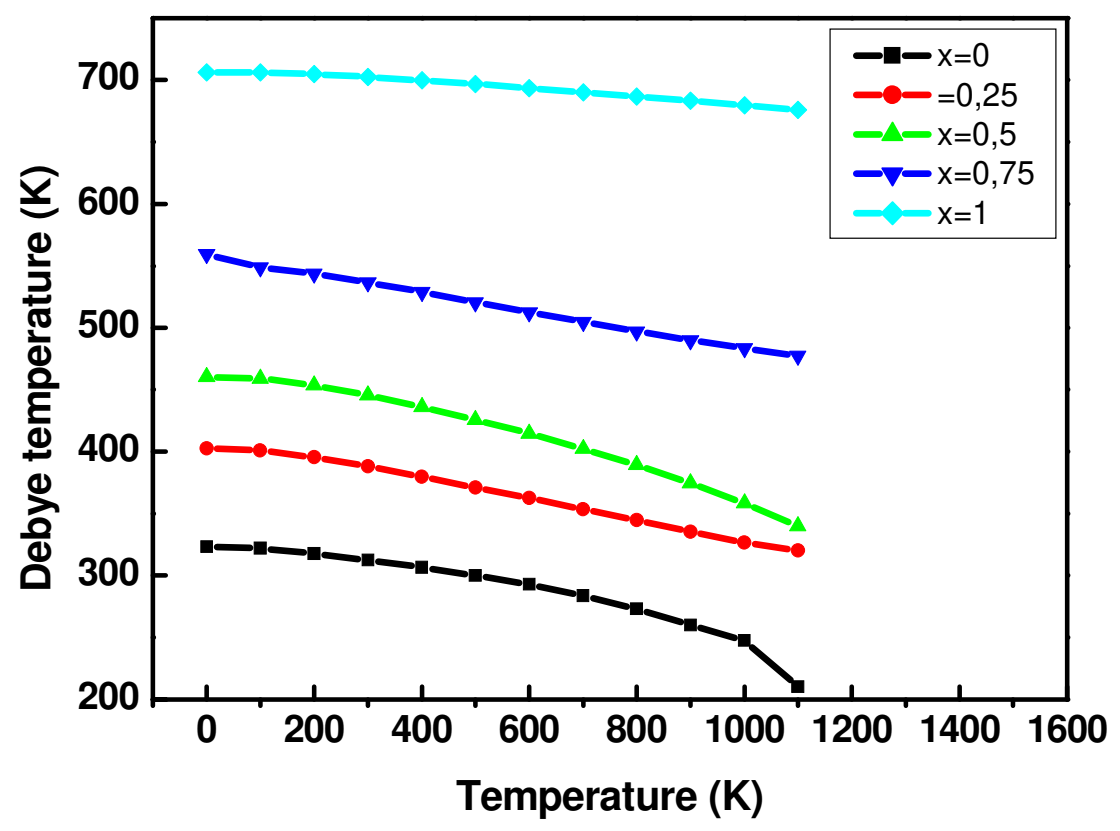

Fig. 17. Variation of the Debye temperature with temperature at $\mathrm{P}=0 \mathrm{GPa}$ of the $\mathrm{GaN}_{\mathrm{x}} \mathrm{As} \mathrm{s}_{1-\mathrm{x}}$ ternary alloys.

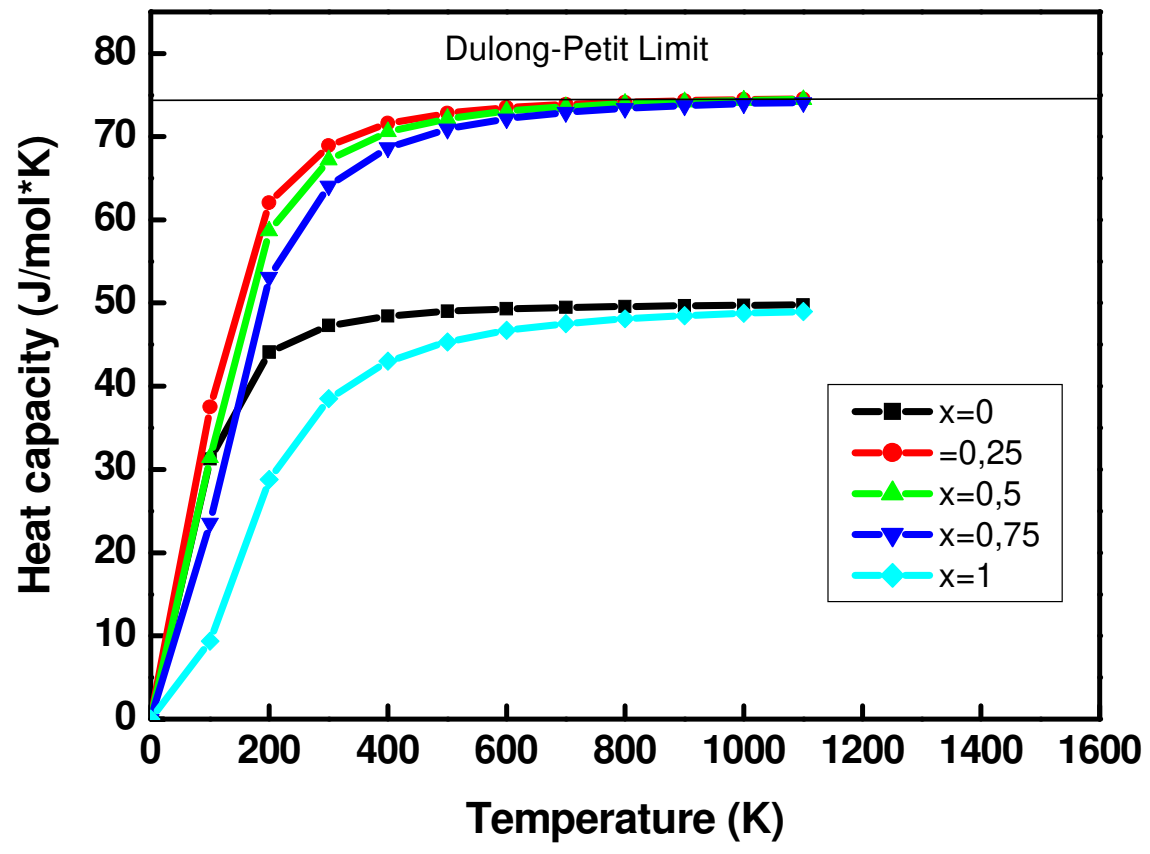

Fig. 18. Variation of the heat capacity with temperature at $\mathrm{P}=0 \mathrm{GPa}$ of the $\mathrm{GaN}_{\mathrm{x}} \mathrm{As}_{1-\mathrm{x}}$ ternary alloys. 


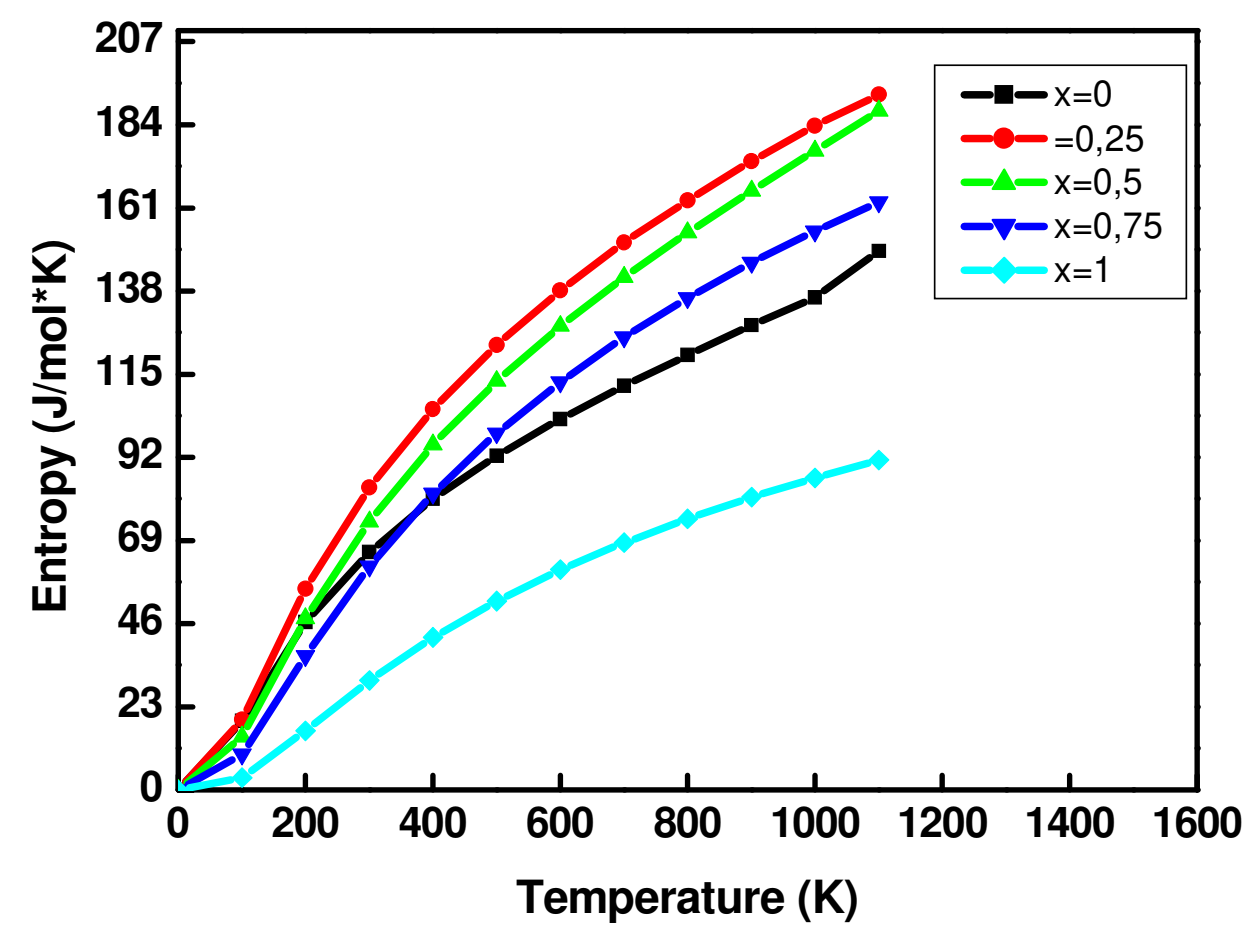

Fig. 19. Variation of the entropy with temperature at $\mathrm{P}=0 \mathrm{GPa}$ of the $\mathrm{GaN}_{\mathrm{x}} \mathrm{As}_{1-\mathrm{x}}$ ternary alloys.

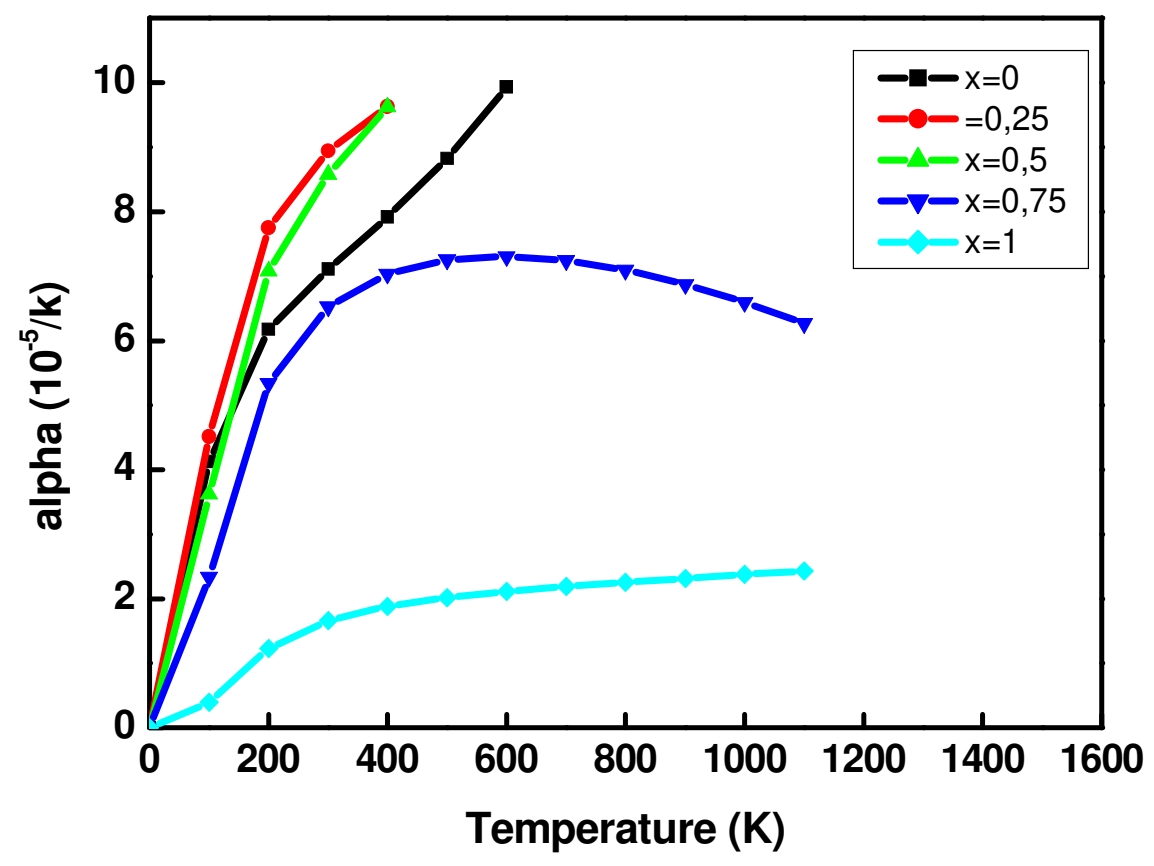

Fig. 20. Variation of the thermal expansion coefficient with temperature at $\mathrm{P}=0 \mathrm{GPa}$ of the $\mathrm{GaN}_{\mathrm{x}} \mathrm{As}_{1-\mathrm{x}}$ ternary alloys. 
